\title{
Genome-wide characterization of the R2R3-MYB transcription factors in pepper (Capsicum spp.) unveils the role of CaMYB101 as repressor in anthocyanin biosynthesis
}

Running head: R2R3-MYB transcriptional repressors in Capsicum spp.

Ying Liu ${ }^{1,2,3 \#}$, Yi Wu ${ }^{1,4 \#}$, Zicheng Wang ${ }^{5}$, Shiya Zhang ${ }^{5}$, Xintong Liu ${ }^{5}$, Yury Tikunov ${ }^{1}$, Richard G.F. Visser $^{1}$, Rob E. Schouten ${ }^{2}$, Leo F.M. Marcelis ${ }^{2}$, Zhao Zhang ${ }^{1,5^{*}}$ and Arnaud Bovy ${ }^{1 *}$

${ }^{1}$ Plant Breeding, Wageningen University and Research, Wageningen, Netherlands.

${ }^{2}$ Horticulture and Product Physiology, Wageningen University and Research, Wageningen, Netherlands.

${ }^{3}$ Graduate School Production Ecology \& Resource Conservation, Wageningen University and Research, Wageningen, Netherlands.

${ }^{4}$ Graduate School Experimental Plant Sciences, Wageningen University and Research, Wageningen, the Netherlands.

${ }^{5}$ Beijing Key Laboratory of Development and Quality Control of Ornamental Crops, Department of Ornamental Horticulture, China Agricultural University, Beijing, China

${ }^{\#}$ These authors made an equivalent contribution

\section{*Authors for correspondence:}

Arnaud Bovy, Plant Breeding, Wageningen University and Research, Droevendaalsesteeg 1, Wageningen, 6708PB the Netherlands. e-mail: arnaud.bovy@wur.nl

Zhao Zhang, Department of Ornamental Horticulture, China Agricultural University, Yuanmingyuan Xilu 2, Beijing 100193, China. Tel. 0086-10-62732724, e-mail: zhangzhao@cau.edu.cn 


\section{Abstract}

2 Fruit colour is one of the most important commercial traits of pepper (Capsicum spp.), a major horticultural 3 crop worldwide. Some pepper accessions temporarily accumulate anthocyanins during fruit development and 4 gradually lose them upon fruit ripening. Meanwhile, anthocyanin biosynthesis gradually stops. However, how 5 this process is exactly regulated is still largely unknown. R2R3-MYB is one of the largest plant transcription 6 factor families, and it is considered the most important regulator for the biosynthesis of anthocyanins and other flavonoids. Although R2R3-MYBs are widely studied in many plants, research in pepper has been

8 limited. In this study, we performed a genome-wide analysis of R2R3-MYBs across three cultivated pepper 9 species (C. annuum, C. baccatum, and C. chinense) involving identification, chromosome localization, gene 10 structure analysis, phylogenetic analysis and collinearity analysis. Candidate R2R3-MYB repressors were 11 further identified based on repression motifs. An R2R3-MYB gene, CaMYB101, was selected based on its 12 high homology with anthocyanin biosynthesis repressors in tomato and petunia as well as its high expression 13 level in fruit when purple pigmentation started to discolour. By using virus-induced gene silencing, 14 CaMYB101 was characterized as an anthocyanin biosynthesis repressor. To our knowledge, CaMYB101 is the first transcriptional repressor associated with anthocyanin biosynthesis identified in pepper.

17 Keywords: pepper, MYB transcription factor, Capsicum annuum, Capsicum chinense, Capsicum baccatum 


\section{Introduction}

Transcription factors (TFs) are involved in stimulating or repressing the transcription of target genes to control physiological and metabolic processes during plant growth and development in response to endogenous or exogenous stimuli (Fuda et al., 2009). Based on their DNA-binding domains, TFs can be classified into different families. The MYB family is one of the largest TF families in plants and is involved in various biological processes including plant growth, circadian clock control, and primary and secondary metabolism regulation (Dubos et al., 2010). A highly conserved DNA-binding domain, known as the MYB domain, contains up to four incomplete repeats at the N-terminus. Each repeat is composed of approximately 50-55 amino acid residues and forms three $\alpha$-helices. The second and third helices form a helix-turn-helix architecture with three spaced tryptophan (or hydrophobic) residues (Ogata et al., 1992; Du et al., 2015). The C-terminus region of MYB proteins is highly variable and responsible for the diverse regulatory functions of MYB TFs. Depending on the number of tandem repeat(s) in the MYB domain, the MYB family has four subfamilies: 1R-MYB (MYB-related), 2R-MYB (R2R3-MYB), 3R-MYB (R1R2R3-MYB) and 4R-MYB (four R1/R2-like repeats) (Dubos et al., 2010). In plants, the first MYB (R2R3-MYB) TF COLORED1 (C1) was discovered from Zea mays and has been identified to be involved in the activation of anthocyanin biosynthesis (Grotewold et al. 1991). Over time, the MYB family has been identified in many plant species. In Arabidopsis, 198 AtMYBs were identified and the tomato genome included 127 SIMYBs (Yanhui et al., 2006; Li et al., 2016). Among the MYB subfamilies, R2R3-MYB is the dominant subfamily with various roles in, for example, flavonoid biosynthesis.

Flavonoids are a large group of secondary metabolites, including flavones, isoflavones, flavonols, anthocyanins and proanthocyanidins. The various flavonoids can serve as antioxidants, defense compounds, signaling molecules and pigments. In plants, there are two types of structural genes: (i) early flavonoid biosynthesis pathway genes (EBGs), encoding chalcone synthase (CHS), chalcone isomerase (CHI), flavonol 3-hydroxylase $(\mathrm{F} 3 \mathrm{H})$ and flavonol 3'-hydroxylase $\left(\mathrm{F}^{\prime} \mathrm{H}\right)$, which are induced as precursors for the downstream genes, known as late biosynthetic genes (LBGs). (ii) The LBGs including dihydroflavonol 4reductase (DFR), anthocyanin synthase (ANS) and UDP-glucose: flavonoid 3-glucosyltransferase (UFGT), leucoanthocyanidin reductase (LAR) and anthocyanin reductase (ANR) which lead to proanthocyanidin and anthocyanin biosynthesis. The regulation of flavonoid biosynthetic structural genes often involves R2R3MYB TFs. The EGBs are activated by independent R2R3-MYBs such as AtMYB11, AtMYB12 and AtMYB111, while LBGs related with anthocyanin biosynthesis are regulated by a MYB-bHLH-WD40 (MBW) complex consisting of a MYB TF, a basic helix-loop-helix (bHLH) and a WD-repeat protein (Xu et al., 2015). There is one exception, F3' $\mathrm{H}$, which is regulated by both independent R2R3-MYBs and an MBW complex (Stracke et al., 2007).

To date, the majority of the flavonoid biosynthesis R2R3-MYBs are transcriptional activators. For example, 
high anthocyanin pigmented apple fruits were observed by overexpression of apple MdMYB10 in cv. 'Royal Gala', together with increased expression of MdCHS, MdCHI, MdF3H, MdDFR, MdANS and MdUFGT (Espley et al., 2007). In grapevine, VvMYB5a leads to an up-regulation of flavonoid biosynthesis and boosted flavonols, anthocyanins and proanthocyanins accumulation (Deluc et al., 2006; Deluc et al., 2008). In addition to flavonoid activators, R2R3-MYB repressors have also been identified and displayed a crucial role in balancing flavonoid biosynthesis. For instance, the grapevine VvMYB4-like and strawberry FaMYB1 suppress the flavonol and anthocyanin accumulation and cause a clear pigmentation loss in flowers (Aharoni et al., 2001; Perez-Diaz et al., 2016). In petunia, overexpression of PhMYB27 causes reduced anthocyanin accumulation, while silencing of this gene enhances anthocyanin accumulation throughout the whole plant including leaves, stems, and flowers (Albert et al., 2014).

Pepper is one of the most popular horticultural crops worldwide. The cultivated pepper comprises several species within the genus Capsicum, such as C. annuum, C. baccatum and C. chinense. The fruits of pepper contain a wide range of health-related secondary metabolites, like carotenoids and flavonoids. Among peppers, there are some purple accessions with a high level of anthocyanins in fruit peels. Moreover, the overall flavonoid content of these purple accessions is generally higher compared to non-purple accessions (Liu et al., 2020). These purple pigments are due to a temporary anthocyanin accumulation before fruit ripening and after ripening the anthocyanin biosynthesis stops and degradation becomes dominant (Yamada et al., 2019). Several R2R3-MYBs have been reported to activate flavonoid biosynthesis in pepper (Borovsky et al., 2004; Zhang et al., 2015). However, no MYB repressors for flavonoid biosynthesis have been identified in pepper yet. Genome-wide identification of the R2R3-MYB gene family has been studied in C. annuum (Wang et al., 2020; Arce-Rodríguez et al., 2021). The recently released pepper genomes make the study of the R2R3MYB gene family in C. baccatum and C. chinense possible. We aim to globally analyse the R2R3-MYB gene family in three Capsicum species and among them identify flavonoid-related R2R3-MYB represosrs in pepper. To accomplish this, a genome-wide analysis of R2R3-MYBs was performed within the three cultivated Capsicum species (C. annuum, C. baccatum and C. chinense), including gene structure, chromosomal location, synteny and phylogeny. As the result, candidate R2R3-MYB repressors in Capsicum spp. were identified. We showed that a R2R3-MYB repressor, named CaMYB101, plays a role in the negative regulation of anthocyanin biosynthesis in pepper. Our results lay a foundation for characterizing R2R3-MYBs among Capsicum spp. and provide a better understanding for flavonoid-related repression mechanism in pepper. 


\section{Results}

\section{Identification of R2R3-MYBs in Capsicum spp. genomes}

The published C. baccatum and C. chinense genome sequences (Table 1) were used for putative R2R3-MYBs identification through HMM profiling (PF00249). After removing redundant proteins by BLASTP through NCBI-CDD, 106 and 110 R2R3-MYB transcription factors were identified in C. baccatum (CbMYBs) and $C$. chinense (CcMYBs), respectively. Meanwhile, 108 R2R3-MYBs of C. annuum (CaMYBs) were derived from the study of Wang et al. (2020). All R2R3-MYBs were named based on their species and chromosomal orders, with details including the accession number, chromosomal location, number of introns and exons as well as the length of coding sequence and protein (Table S1-S3). The longest CaMYB is CaMYB82 with 995 amino acids and the shortest is CaMYB58 with 110 amino acids. CbMYB21 is the longest MYB protein of all Capsicum spp., and contains 1210 amino acids, while CbMYB10 is the shortest CbMYB protein with 152 amino acids. The length of CcMYB proteins varied from 137 (CcMYB66) to 1156 (CcMYB42) amino acids.

\section{Sequence conservation within the $R 2$ and $R 3$ domains}

Multiple sequence alignment analyses of all putative R2R3-MYBs derived from three Capsicum spp. as well as from Arabidopsis were performed to demonstrate the feature of homologous domain sequences and the corresponding amino acid frequency. Similar to Arabidopsis, the R2 and R3 domains of all the R2R3-MYBs among Capsicum spp. were highly conserved (Figure 1). Meanwhile, the tryptophans (W) are highly conserved in R2 (three) and R3(two) domains.

\section{Chromosomal localization and collinearity/ synteny analysis of Capsicum R2R3-MYBs}

The Ca-, Cb- and CcMYBs were physically mapped throughout all 12 chromosomes in C. annuum, C. baccatum and $C$. chinense, respectively (Figure 2). In total 11 CaR2R3-MYBs, 9 CbR2R3-MYBs and 5 CcR2R3-MYBs were located on unanchored scaffolds and assigned to Chr. 00 (Table S1-S3). The distribution of R2R3-MYBs among three Capsicum spp. genomes was also not congruent. C. annuum and C. chinense had a relatively high density of R2R3-MYBs at the top and bottom of chromosomes compared to C. baccatum. The maximum and minimum number of R2R3-MYBs allocated per genome were similar. In C. annuum, Chr. 03 contained the most CaR2R3-MYBs, 12, whereas Chr. 08 had the lowest number of CaR2R3-MYBs, four, over all chromosomes (Figure 2A). In C. baccatum, Chr. 01, 03, 05, 06 and 07 contained the highest number (10) CbR2R3-MYBs, while Chr. 04 and 09 had the lowest number of four CbR2R3-MYBs (Figure 2B). In $C$. chinense, Chr. 06 had the highest number (13) CcR2R3-MYBs while Chr. 08 contained only two CcR2R3MYBs (Figure 2C).

In total, 119 syntenic gene pairs were identified (Table 2, Supplemental Table S4), including 95 pairs of interspecies orthologs and 24 pairs of intra-species paralogs. To be specific, 44 gene pairs were between $C$. annuum and $C$. chinense, 30 gene pairs were between $C$. annuum and $C$. baccatum and 21 gene pairs were 
between C. baccatum and C. chinense (Figure 3, Supplemental Table S4). Among the 24 syntenic paralogs, 21 gene pairs were inter-chromosomal, while the rest three pairs were located on chromosome 2 (CaMYB12CaMYB19, CaMYB13-CaMYB20 and CcMYB14-CcMYB22). The synonymous (Ks) and non-synonymous (Ka) values were used to determine the selection pressures. The $\mathrm{Ka} / \mathrm{Ks}$ ratios for segmental duplication were between 0.11 and 0.53 through syntenic paralogs. In the syntenic orthologs, two out of 95 pairs showed Ka/Ks ratios larger than 1.0, indicating a positive selection on these gene pairs (for improved function), while the rest 93 pairs harboured the $\mathrm{Ka} / \mathrm{Ks}$ smaller than 1.0 , indicating stabilising selection (to maintain function).

\section{Gene structure analysis of Capsicum R2R3-MYBs}

Phylogenetic analyses were performed on 108 CaR2R3-MYBs, 106 CbR2R3-MYBs and 110 CcR2R3-MYBs, respectively (Supplementary Figure S1). In addition, a comprehensive phylogenetic analysis was done on 125 Arabidopsis R2R3-MYBs, 324 summed R2R3-MYBs in three Capsicum spp. and 36 published anthocyanin related MYBs (Table 3, Supplemental Figure S2). The published anthocyanin-related R2R3-MYBs were composed of activators and repressors of anthocyanin biosynthesis (Table 3).

The exon-intron structure pattern of the MYBs was further investigated in C. annuum, C. baccatum and $C$. chinense (Supplementary Figure 2). Generally, over 95\% of R2R3-MYBs in Capsicum spp. had at least one intron over the entire gene sequence. The majority of R2R3-MYBs in pepper had a structure which was composed of two introns with three exons (respectively 70 of 108 CaMYBs, 69 of 106 CbMYBs and 72 of 110 CcMYBs).

\section{Identification of $\mathrm{R} 2 \mathrm{R} 3-\mathrm{MYB}$ repressors}

In total 53 candidate R2R3-MYB repressors were identified based on their repression motifs in Capsicum spp. (Supplementary Figure 2, Table 4). To be specific, 47 candidate R2R3-MYB repressors only had an EAR motif (15 CaMYBs, 15 CbMYBs and 17 CcMYBs), three had a LxLxPP motif (CaMYB37, CbMYB32 and CcMYB40) and three had both EAR- and LxLxPP motifs (CaMYB16, CbMYB13 and CcMYB16).

To identify anthocyanin-related R2R3-MYB repressors in pepper, a phylogenetic analysis was performed using candidate pepper MYB repressors together with 36 published anthocyanin MYB regulators from other plant species (Table 3, Figure 4). Meanwhile, CaMYB101, CbMYB89 and CcMYB92 were characterized within one cluster (red curve in Figure 4), together with two identified R2R3-MYB repressors from the Solanaceae family (petunia PhMYB27 and tomato SIMYBL2) (Albert et al., 2011; Zhang et al., 2019). In addition, two strawberry R2R3-MYB repressors (FaMYB1 and FcMYB1) and one Medicago truncatula R2R3-MYB repressor (MtMYB2) were the closest orthologs to the cluster of CcMYB87, CcMYB108, CbMYB67 and CaMYB70 and the cluster of CaMYB101, CbMYB89 and CcMYB92. Moreover, CaMYB16, CbMYB13 and CcMYB16 were characterized together with an identified apple R2R3-MYB repressor (MdMYB6), while CcMYB91 was characterized together with an identified Arabidopsis R2R3-MYB repressor (AtMYB60). 
CaMYB101, CbMYB89 and CcMYB92 had high amino acid similarity with other Solanaceae family members such as tomato SIMYBL2 and petunia PhMYB27, especially the R2, R3 domain and EAR motif (Figure 4B). It showed that the conserved R2, R3 domain and EAR motif of CaMYB101, CbMYB89 and CcMYB92 were identical. The tomato SIMYBL2 had two EAR motifs, LxLxL and DLNxxP, compared with the other four MYBs with one EAR motif.

\section{Expression profile of candidate CaR2R3-MYB repressors in different tissues}

The expression profile of 17 candidate R2R3-CaMYB repressors (Table 4), based on the RNA-seq transcriptome analysis of $C$. апnиum cv. Zunla (Qin et al., 2014), revealed expression variation in different tissues and fruit developmental stages (Figure 5). Eight (CaMYB37, CaMYB45, CaMYB67, CaMYB70 CaMYB72, CaMYB91, CaMYB92 and CaMYB101) out of 17 R2R3-CaMYB repressors showed a relatively high expression level in fruits, especially at pre-breaker stage (3-4cm fruit length) and at post breaker stage (5 days after breaker fruits), respectively (Figure 5).

\section{Functional analysis of CaMYB101 in C. annuum cv. Tequila}

The $C$. annuиm cv. Tequila is a transiently purple-fruited genotype of which the fruit is green in the early stages of fruit development and then turns purple and eventually red when fully ripe. To explore the involvement of MYB repressors in the regulation of fruit peel color in cv. Tequila, we investigated the candidate gene CaMYB101. CaMYB101 is a candidate R2R3-MYB repressor characterized by an EAR motif and, meanwhile, its orthologs in C. baccatum (CbMYB89) and C. chinense (CcMYB92) were also identified as repressors with an EAR motif (Table 4). Based on the phylogenetic analysis and transcriptome profiling, CaMYB101 was selected as a candidate gene. CaMYB101 had high homology to tomato SIMYBL2 and petunia PhMYB27 (Figure 4) that are involved in the negative regulation of anthocyanin biosynthesis. The published transcriptome profile also demonstrated a relatively high expression level of CaMYB101 in pepper fruits (cv. Zunla) (Figure 5), indicating it may function in fruits. In addition, the duplication analysis showed that it did not undergo a duplication event, which minimized the paralog-caused interference and, therefore, functional redundancy. First of all, the expression of CaMYB101 in purple pepper background, cv. Tequila, was verified by RT-qPCR in different tissues and fruits at different developmental stages (Figure 6). The expression of CaMYB101 increased from the fertilized ovary to the fruit turning stage (28 DAA) and then decreased until the fruits were fully ripe.

To investigate the role of CaMYB101 in anthocyanin biosynthesis in pepper fruit, three repeated virusinduced gene silencing (VIGS) experiments were performed with pTRV2::GUS constructs as control. All three VIGS experiments showed the reproducible results. The pTRV2::GUS infected plants produced only green leaves (GUS-GL), while the pTRV2::CaMYB101 infected plants produced both green leaves (MYBGL) and purple leaves (MYB-PL) that was due to anthocyanin accumulation (Figure 7A). These results indicated that CaMYB101 probably repressed anthocyanin biosynthesis in pepper. To verify the silencing 
efficiency, the expression of CaMYB101 was examined in the silenced leaves. Compared with the control plants (GUS-GL), the expression of CaMYB101 was significantly reduced in leaves of CaMYB101 silenced plants (in both MYB-GL and MYB-PL) (Figure 7A), which indicated that CaMYB101 was silenced successfully. Additionally, compared with MYB-GL, the relative expression level of CaMYB101 was significantly lower in MYB-PL, which further implied the association of CaMYB101 with anthocyanin accumulation.

In the early fruit developmental stages, the ovaries of pTRV2::GUS infected plants were green, while the ovaries of CaMYB101 silenced plants showed intense purple sectors due to anthocyanin accumulation (Figure 7B). However, the CaMYB101 silenced fruits that developed from purple ovaries (42 DAA) showed a faster purple discolouration than the pTRV2::GUS fruits (42 DAA) (Figure 7C). We examined the expression of CaMYB101 in the silenced ovaries and fruits. The clear boundary of anthocyanin pigmentation in CaMYB101 silenced ovaries (Figure 7B) enabled precise sampling of the purple parts (MYB-PO) and green parts (MYBGO). In the green parts of CaMYB101 silenced ovaries (MYB-GO), the expression of CaMYB101 was also significantly reduced, compared to the green ovaries of control (GUS-GO) (Figure 7B), suggesting that CaMYB101 was successfully silenced. However, unexpectedly, CaMYB101 showed a significantly higher expression in the purple part of CaMYB101 silenced ovaries (MYB-PO) than in the green part of the same ovaries (MYB-GO) and the green ovaries of control (GUS-GO). At a later fruit developmental stage (42 DAA), consistent with leaves, a significantly lower expression of CaMYB101 was detected in pTRV2::CaMYB101 fruits than in pTRV2::GUS fruits (Figure 7C), which indicated the successful silencing of CaMYB101 in fruits.

The expression of anthocyanin biosynthetic genes was verified in ovaries of pTRV2::CaMYB101 and pTRV2::GUS infiltrated plants. The majority of tested anthocyanin biosynthetic genes were significantly upregulated upon CaMYB101 silencing, including regulatory genes $\mathrm{CaMYB}_{A}$ (CaMYB82), CabHLH, EBGs CaCHS2, CaCHI2, CaF3H and CaF3'H as well as LBGs CaF3'5' H, CaDFR, CaANS and CaUFGT. These genes all showed significantly higher expression level in MYB-PO compared to MYB-GO and/or GUS-GO (Figure 8). 


\section{Discussion}

\section{Identification and characterization of R2R3-MYBs in three Capsicum species}

213 At present, the pepper (Capsicum. spp) genome sequences have been released for C. annuum, C. baccatum and C. chinense (Kim et al., 2014; Qin et al., 2014; Kim et al., 2017). In plants, complete and accurate gene annotation enables evolutionary and functional studies of gene families. However, different gene families are not completely annotated in the pepper genus. The MYB family is one of the largest transcription factor families, with the R2R3-MYBs as the main subfamily (Stracke et al., 2001). Nevertheless, there is no comprehensive comparison of R2R3-MYBs across different pepper genomes and most of their functions are unclear. As one of the most cultivated species among the Capsicum genus, 108 and 116 C. annuum R2R3MYBs have been genome-widely analyzed based on the Zunla 1.0 genome sequence by Wang et al. (2020) and Arce-Rodríguez et al. (2021), respectively. The reason for the disparity in different number of R2R3MYBs could be that other known R2R3-MYB plant proteins were also used for identification in ArceRodríguez et al. (2021) work. The 108 CaR2R3-MYBs that Wang et al. (2020) identified in C. annuum were used for further analysis in this study, together with 106 CbR2R3-MYBs and 110 CcR2R3-MYBs we identified in C. baccatum and C. chinense, respectively. The number of R2R3-MYBs we identified is similar throughout three Capsicum spp., comparable to Solanum tuberosum L. (111) (Li et al., 2020), lower than Solanum lycopersicum (121) (Zhao et al., 2014) and Arabidopsis thaliana (126) (Stracke et al., 2001), and

The genetic conservation, divergence and gene duplication cases of all R2R3-MYBs were studied throughout Capsicum spp. including among species (interspecies) and within species (intraspecies). The R2R3-MYB proteins of the three Capsicum spp. and Arabidopsis shared highly conserved sequences within the R2 and R3 MYB domains based on amino acid frequencies (Figure 1), which confirmed the conserved nature of pepper MYB domains. This is consistent with the previous studies of R2R3-MYBs in Arabidopsis (Dubos et al., 2010). The R2 domain has three conserved tryptophans and the R3 domain has two, where the first tryptophan (missing in R3) was always replaced by a hydrophobic amino acid. These results are consistent with studies in other Solanaceous members such as tomato (Zhao et al., 2014), eggplant (Wang et al., 2016) and potato (Li et al., 2020).

Even though the pepper R2R3-MYBs were distributed unevenly on 12 chromosomes within each genome, the overall R2R3-MYB distribution of $C$. annuum and $C$. chinense was more similar compared to $C$. baccatum (Figure 2). In addition, $C$. annuum and C. chinense shared more syntenic orthologs (44 pairs) than C. annuum 
S4). Both chromosomal distribution and syntenic relationship suggested that $C$. annuum and $C$. chinense were evolutionarily closer, which is in agreement with Kim et al. (2017) who reported that divergence first occurred between $C$. baccatum and the progenitor of $C$. annuum and $C$. chinense. Gene duplication plays an important role in the expansion of the R2R3-MYB family. In addition, the Ka/Ks ratio of over $98 \%$ (117/119) of R2R3MYBs syntenic gene pairs is smaller than 1.0, which indicates that the R2R3-MYB subfamily underwent purifying selection.

\section{Characterization of pepper R2R3-MYB repressors}

Previous research shows that the R2R3-MYB subfamily plays an important role in anthocyanin synthesis. For example in pepper, an anthocyanin activator, $\mathrm{CaMYB}_{A}$, has been functionally identified (Borovsky et al., 2004; Zhang et al., 2015). However, no anthocyanin MYB repressor has been identified yet in pepper. We phylogeneticly analysed the predicted pepper R2R3-MYBs with 125 Arabidopsis R2R3-MYBs and 34 anthocyanin related R2R3-MYB activators and repressors (Table 3, Supplemental Figure S1) to identify putative anthocyanin-related pepper R2R3-MYBs. The orthologous R2R3-MYBs of C. annuum, C. baccatum and $C$. chinense were clustered tightly. Meanwhile, some R2R3-MYBs were clustered with anthocyaninrelated R2R3-MYBs. For example, CaMYB101, CbMYB89 and CcMYB92, were within one cluster together with FaMYB1, FcMYB1, MtMYB2, PhMYB27 and SIMYBL2, suggesting that they have similar functions (Figure 4A, Supplemental Figure 1).

The EAR motif is the most predominant transcriptional repression motif in plants, with different sequence patterns, i.e. LxLxL and DLNxxP, and can be used to identify transcriptional repressors (Kagale and Rozwadowski, 2011). In our study, 53 Capsicum spp. R2R3-MYBs were identified as repressors by containing at least one EAR motif. A phylogenetic analysis of these 53 candidate repressors and known anthocyanin R2R3-MYB activators and repressors (Table 5A) revealed that (i) CaMYB101, CbMYB89 and CcMYB92 were closely clustered with repressor PhMYB27, SIMYBL2, MtMYB2, FaMYB1 and FcMYB1, (ii) CaMYB16, CbMYB13 and CcMYB16 were clustered together with repressor MdMYB6 and (iii) CcMYB91 was clustered together with repressor AtMYB60 from Arabidopsis, indicating their potential function as anthocyanin repressors. Based on this phylogenetic analysis, it was also clear that most candidate repressors had three sets of orthologs in the three pepper genomes and therefore we focused on CaR2R3-MYB repressors, since $C$. annuum is the most widely cultivated species within Capsicum spp. The17 CaR2R3-MYB repressors exhibited varied transcript profiles in different tissues according to the public C. annuum (Zunla v1.0) RNA-seq data (Figure 5) (Qin et al., 2014). The relative transcript abundance of CaMYB37, CaMYB45, CaMYB67, CaMYB70, CaMYB72, CaMYB91, CaMYB92 and CaMYB101 were dependent on the fruit development stage. In purple pepper fruits of cv. Tequila, anthocyanin accumulation is mainly initiated at an early fruit stage (10 DAA) and would degrade during ripening (Liu et al., 2018). The RNAseq data revealed that CaMYB101, whose encoded protein sequence clustered with the known anthocyanin MYB repressors 
PhMYB27 and SIMYBL2, showed high relative-expression levels at the pre-breaker and breaker stages when fruit was turning red. Therefore, CaMYB101 was selected for further functional study.

\section{CaMYB101 represses anthocyanin biosynthesis via a negative-feedback loop?}

The termination of anthocyanin biosynthesis in purple pepper fruits upon ripening provides us with an opportunity to investigate anthocyanin biosynthesis repression mechanisms. The relative gene expression level of CaMYB101 in different tissues of cv. Tequila confirmed its expression in fruits (Figure 6). In addition, the expression of CaMYB101 was strongly associated with purple pigmentation in fruits, which agreed with the expression of $\operatorname{TrMYB133}$, an R2R3-MYB repressor for anthocyanin biosynthesis in red forage legumes (Albert, 2015). In addition, the TrMYB133 as well as PhMYB27, the petunia ortholog of CaMYB101 (Figure 4), both provide feedback repression for anthocyanin biosynthesis through their transcriptional activation by the MBW complexes containing anthocyanin R2R3-MYB activators, and this feedback repression might be conserved across eudicots (Albert et al., 2014; Albert, 2015). Notably, CaMYB101 had a significantly higher expression level in leaf and stem of cv. Tequila than in fruits, which was different from the RNA-seq profile (Figure $5 \&$ 6). This could be due to the fact that Qin et al., (2014) used a non-purple cultivar, i.e. C. annuum cv. Zunla for RNA-seq.

Since anthocyanin R2R3-MYB repressors suppress anthocyanin biosynthesis, we expected that virus- induced silencing of such a repressor would lead to increased anthocynain accumulation by VIGS. Through inoculation of pTRV2::CaMYB101 in cv. Tequila at the cotyledon stage, we found anthocyanin accumulation in both ovaries and leaves, resulting in ovaries and leaves being partially purple and partially green (Figure 7A and 8B). However, VIGS of CaMYB101 did not result in a more purple fruit phenotype in the later stages of fruit ripening, but instead it accelerated discoloration of purple fruits (Figure 7C). At the same time, CaMYB101 showed a lower expression in leaves and fruits of pTRV2::CaMYB101 plants compared to pTRV2::GUS plants, confirming the successful silencing of CaMYB101 in pTRV2::CaMYB101 plants (Figure 7A and 8B). R2R3-MYB repressors suppress anthocyanin biosynthesis via two mechanisms. On the one hand, R2R3-MYB repressors inhibit the assembly of functional MBW complexes by competing with MYB activators to bind to a bHLH transcription factor (LaFountain and Yuan, 2021). On the other hand, they suppress the transcription of anthocyanin structural genes through their repressive motifs. CaMYB101 has a bHLH binding domain and an EAR motif (Figure 4), suggesting it may have both repressive abilities.

In purple areas of pTRV2::CaMYB101 ovaries, the anthocyanin regulator genes, including R2R3-MYB activators $\mathrm{CaMYB}_{A}$, and most structural genes were activated and showed higher transcript levels than in green parts of the pTRV2::CaMYB101 and pTRV2::GUS ovaries. (Figure 8A-C). Unexpectedly, the expression level of CaMYB101 in purple areas of pTRV2::CaMYB101 ovaries was also significantly higher compared to green parts of pTRV2::CaMYB101 ovaries, as well as in green pTRV2::GUS ovaries (Figure 7B). The high expression level of CaMYB101 in the purple area of pTRV2::CaMYB101 ovaries is in line with 
312 a study that also reported a high expression level of its tomato orthologous gene SIMYBL2 in purple fruits of 313 transgenic tomato lines overexpressing BrTT8 (Zhang et al., 2019), suggesting that SlMYBL2 was 314 transcriptionally activated to counterbalance the active transcription of the MBW complex to prevent 315 excessive anthocyanin synthesis. Zhang et al. (2019) proposed that an excess of anthocyanin synthesis could 316 act as a signal to activate the expression of SIMYBL2. Similarly, AtMYB4, PhMYB27 and Tr-MYB133 are 317 direct targets of MBW complexes containing anthocyanin R2R3-MYB activators and they in turn provide 318 negative feedback regulation to MBW complexes (Jin et al., 2000; Albert et al., 2011; Albert, 2015). We 319 hypothesize that anthocyanin accumulation in the purple ovary is due to the initial silencing of CaMYB101 by 320 VIGS. We further hypothesise that either high anthocyanin levels or high transcription levels of the MBW 321 complex act as a signal to activate CaMYB101 expression to avoid overproduction of anthocyanins in a 322 negative-feedback loop. It also indicates that the VIGS effect that should be still present in the silenced tissue 323 is not enough to cope with that feedback induction effect.

324 Even though VIGS of CaMYB101 caused anthocyanin accumulation in both pepper leaves and ovaries, 325 feedback regulation seemed not to occur in leaves (Figure 7A), suggesting that different molecular 326 mechanisms of anthocyanin pigmentation may exist in vegetative tissues and in ovaries. However, why 327 silencing of CaMYB101 accelerated anthocyanin discolouration in fruits is still unclear (Figure 7C) and this needs further research. It is recommended to sample more fruit stages during fruit development, especially at an earlier stage to see (i) if the proposed negative feedback loop is also detectable in fruits to overcome the silencing. However, it is worth to realise that fruits probably produce CaMYB101 as part of their "normal" anthocyanin regulation (Figure 6). (ii) if the transient expression of anthocyanin biosynthetic genes in silenced fruits is ahead of time compared to non-silenced fruits. Last but not least, a complete knockout of CaMYB101 would be interesting, since in that case there is no compensation caused by re-activation of this gene. 


\section{Conclusion}

336 The present study provides an overview of the pepper R2R3-MYB gene family by conducting a 337 comprehensive global genome analysis of three Capsicum.spp., with specific focus on R2R3-MYB repressors. 338 Functional analysis of CaMYB101 showed that CaMYB101 functions as a repressor of anthocyanin 339 accumulation in pepper leaves and ovaries. Our study sheds new light on the negative regulation of 340 anthocyanin biosynthesis in pepper and demonstrates the potential of VIGS to study the function of 341 anthocyanin-related candidate genes in this important horticultural crop. This may lead to novel breeding strategies to modify the anthocyanin content of pepper. 


\section{Methods}

\section{Plant material}

Bell pepper (Capsicum annuиm) cv. Tequila (Enza Zaden) was grown under standard greenhouse conditions in Wageningen, the Netherlands. Nine plants were grown for determining gene expression profile of CaMYB101 in different plant tissues. Plant leaf, stem, seed, ovary, flower and fruits at day after anthesis (DAA) of 5, 7, 21, 28, 42 and 56 were sampled for tissue specific expression. Tissues and fruits from each three plants were pooled together as one biological replicate.

\section{Identification of the R2R3-MYB subfamily genes in Capsicum spp.}

Multiple de novo pepper genome sequences of Capsicum baccatum and Capsicum chinense were downloaded from the Pepper Genome Platform (http://peppergenome.snu.ac.kr/). A Hidden Markov Models (HMM) profile of MYB DNA-binding domain (PF00249) was downloaded from Pfam database (http://pfam.xfam.org/). It was used as a query to search the $C$. baccatum and $C$. chinense genomes to identify all MYB containing sequences with an E-values $<1 \mathrm{e}^{-3}$. All candidate protein sequences were examined using the NCBI conserved domain database (CDD) (https://www.ncbi.nlm.nih.gov/Structure/cdd/wrpsb.cgi) ExPASy (https://web.expasy.org/protparam/) to verify the presence of R2 and R3 domains. The R2R3-MYB genes of C. annuиm used in this study were identified by Wang et al. (2020). The pepper R2R3-MYBs were named based on their species, namely CaMYB for $C$. annuum, CbMYB for $C$. baccatum and CcMYB for $C$. chinense, and numbered based on chromosomal orders (chr1 - chr12, chr0). The amino acid sequences of R2 and R3 MYB repeats of CaMYBs, CbMYBs and CcMYBs were aligned with ClustalW (MEGA-7) and manually adjusted referring to Arabidopsis (Dubos et al., 2010). The sequence logos of R2 and R3 MYB repeats were constructed by WebLogo (Crooks et al., 2004). The chromosomal distribution of pepper R2R3-MYBs was mapped using Mapchart 2.2 software (Voorrips, 2002).

\section{Gene structure motif and phylogenetic analysis}

The MEME v5.1.0 online tool was used for the conserved domain investigation. The map of exon-intron structure of Capsicum spp. R2R3-MYBs was constructed by TBtools software using coding sequences with the corresponding protein sequences (Chen et al., 2020). The complete protein sequences of Capsicum spp. R2R3MYBs were aligned by ClusterW method then the phylogenetic analysis of R2R3-MYBs was constructed by NJ method with bootstrap test 1000 replicates using MEGA6.0.

\section{Collinearity/Synteny analyses}

The Capsicum spp. genome protein sequences and gene structure annotation file were downloaded from Pepper Genome Platform (http://peppergenome.snu.ac.kr/). The Basic Local Alignment Search Tool (BLAST+, NCBI) was used to find the local similarity between sequences with e-value $<1 \mathrm{e}^{-5}$, number of hits and aligns was set to 5 . Then 
the obtained sequences together with the gene structure annotation file was used to investigate the collinearity/syntenic relationship between Capsicum spp. by using a Multiple Collinearity Scan toolkit (Wang et al., 2012). When determining collinearity relationship, the smallest block of intra-species genes was filtered to contain at least 5 pairs and the smallest block of inter-species genes was filtered to contain at least 30 pairs. In this way, the syntenic R2R3-MYB gene pairs were selected. TBtools software was used for the calculation of synonymous (Ks) and non-synonymous $(\mathrm{Ka})$ value.

\section{Identification of repression motif-containing R2R3-MYB proteins}

Repression motifs, included EAR motif (LxLxL, DLNxxP), TLLLFR motif (TLLLFR), R/KLFGV motif $(\mathrm{R} / \mathrm{KLFGV})$ and LxLxPP motif (LxLxPP) were screened across all R2R3-MYBs in three pepper genomes (Kagale and Rozwadowski, 2011).

\section{Expression Profiles of CaMYB Genes Based on RNA-Seq}

The expression levels of R2R3-MYBs in Capsicum annuum cv. Zunla have been investigated in the different growth development. The RNA-seq atlas was downloaded from China National GeneBank (https://db.cngb.org/search/project/CNPhis0000547/) (Qin et al., 2014). Six different organs including root, stem, leaf, bud, flower and fruits were used for analysis. Furthermore, the relative gene expression level of R2R3=-MYBs were calculated by Reads Per Kilo bases per Million (RPKM). The hierarchical clustering was carried out with Pearson's correlation distance and the gene clusters were clustered by gene expression.

\section{VIGS and agrobacteria inoculation}

The specific region of CaMYB101 (Capana00g002497) used for silencing was selected by SGN VIGS Tool (Fernandez-Pozo et al., 2015). A 223 bp fragment of CaMYB101 was amplified within the specific region using primers vigsCaMYB101-For (5'- CACCAGGATCTTGGTCTAAACAAGAAGA -3') and vigsCaMYB101-Rev (5'- CCTATTGCCAAGAAGAGCAT -3') from cv. Tequila cDNA to design VIGS construct. The fragment was cloned into pTRV2 vector (Liu et al., 2002), then the pTRV2 vectors carrying specific CaMYB101 fragment were transformed into Agrobacterium tumefaciens strain GV3101. A. tumefaciens culture containing pTRV1, pTRV2::CaMYB101, pTRV2::PDS or pTRV2::GUS was prepared for VIGS experiment as described by Romero et al. (2011). The pTRV1 culture was mixed with pTRV2 culture in a 1:1 ratio. Then TRV infection was done through mixed culture infiltration on the abaxial of cotyledon of 100 three-week-old cv. Tequila seedlings using syringes without a needle. Among them, 45 plants were inoculated with pTRV2::CaMYB101, 45 plants were inoculated with pTRV2::GUS and 10 plants were inoculated with pTRV2::PDS.

\section{Real-Time Quantitative PCR}

The qPCR reaction was prepared with iQ ${ }^{\mathrm{TM}}$ SYBR Green Supermix kit (Bio-Rad, USA) then detected by C1000 Touch $^{\mathrm{TM}}$ Thermal Cycler (Bio-Rad CFX96 Real-Time system, USA). Relative expression levels of candidate genes were calculated with the $2^{-\Delta \Delta \mathrm{CT}}$ method (Livak and Schmittgen, 2001). Gene specific primers were designed by 
bioRxiv preprint doi: https://doi.org/10.1101/2021.08.24.457473; this version posted September 13, 2021. The copyright holder for this preprint (which was not certified by peer review) is the author/funder, who has granted bioRxiv a license to display the preprint in perpetuity. It is made available under aCC-BY-NC-ND 4.0 International license.

408 Primer3Plus (http://www.bioinformatics.nl/cgi-bin/primer3plus/primer3plus.cgi) and the primers used in this paper 409 are listed in Supplemental Table S5. 


\section{Author contribution}

YL defined the research question, proposed the methodology and the experimental design. YL and YW carried out the experiments and analysed the experimental data together. ZZ, ZW, SZ and XL performed the bioinformatic analysis. YL and YW wrote the first draft, ZZ revised it. YT, RV, LM, RS and AB provided comments for the final version. All authors have approved the manuscript. This paper has not been accepted or published elsewhere.

\section{Funding}

The authors are grateful for the financial support provided by China Scholarship Council (CSC) under grant number 201607720005 and 201707720017. 


\section{Reference}

Aguilar-Barragán A, Ochoa-Alejo N (2014) Virus-induced silencing of MYB and WD40 transcription factor genes affects the accumulation of anthocyanins in chilli pepper fruit. Biologia Plantarum 58: 567-574

Aharoni A, De Vos CHR, Wein M, Sun Z, Greco R, Kroon A, Mol JNM, O'Connell AP (2001) The strawberry FaMYB1 transcription factor suppresses anthocyanin and flavonol accumulation in transgenic tobacco. Plant Journal 28: 319-332

Albert NW (2015) Subspecialization of R2R3-MYB repressors for anthocyanin and proanthocyanidin regulation in forage legumes. Frontiers in Plant Science 6

Albert NW, Davies KM, Lewis DH, Zhang H, Montefiori M, Brendolise C, Boase MR, Ngo H, Jameson PE, Schwinn KE (2014) A conserved network of transcriptional activators and repressors regulates anthocyanin pigmentation in eudicots. The Plant Cell 26: $962-980$

Albert NW, Lewis DH, Zhang H, Schwinn KE, Jameson PE, Davies KM (2011) Members of an R2R3-MYB transcription factor family in Petunia are developmentally and environmentally regulated to control complex floral and vegetative pigmentation patterning. Plant J 65: 771-784

Arce-Rodríguez ML, Martínez O, Ochoa-Alejo N (2021) Genome-wide identification and analysis of the myb transcription factor gene family in chili pepper (Capsicum spp.). International Journal of Molecular Sciences 22: 1-24

Bond DM, Albert NW, Lee RH, Gillard GB, Brown CM, Hellens RP, Macknight RC (2016) Infiltration-RNAseq: TRANSCRIPTOME profiling of Agrobacterium-mediated infiltration of transcription factors to discover gene function and expression networks in plants. Plant Methods 12: 1

Borevitz JO, Xia Y, Blount J, Dixon RA, Lamb C (2000) Activation tagging identifies a conserved MYB regulator of phenylpropanoid biosynthesis. Plant Cell 12: 2383-2393

Borovsky Y, Oren-Shamir M, Ovadia R, De Jong W, Paran I (2004) The A locus that controls anthocyanin accumulation in pepper encodes a MYB transcription factor homologous to Anthocyanin2 of Petunia. Theoretical and Applied Genetics 109: 23-29

Cavallini E, Zenoni S, Finezzo L, Guzzo F, Zamboni A, Avesani L, Tornielli GB (2014) Functional diversification of grapevine MYB5a and MYB5b in the control of flavonoid biosynthesis in a petunia anthocyanin regulatory mutant. Plant and Cell Physiology 55: 517-534

Chen C, Chen H, Zhang Y, Thomas HR, Frank MH, He Y, Xia R (2020) TBtools: An Integrative Toolkit Developed for Interactive Analyses of Big Biological Data. Molecular Plant 13: 1194-1202

Crooks GE, Hon G, Chandonia JM, Brenner SE (2004) WebLogo: A sequence logo generator. Genome Research 14: 1188-1190

Deluc L, Barrieu F, Marchive C, Lauvergeat V, Decendit A, Richard T, Carde JP, Mérillon JM, Hamdi S (2006) Characterization of a grapevine R2R3-MYB transcription factor that regulates the phenylpropanoid pathway. Plant Physiology 140: 499-511

Deluc L, Bogs J, Walker AR, Ferrier T, Decendit A, Merillon JM, Robinson SP, Barrieu F (2008) The transcription factor VvMYB5b contributes to the regulation of anthocyanin and proanthocyanidin biosynthesis in developing grape berries. Plant Physiol 147: 2041-2053

Du H, Liang Z, Zhao S, Nan MG, Tran LSP, Lu K, Huang YB, Li JN (2015) The evolutionary history of R2R3-myb proteins across 50 eukaryotes: New insights into subfamily classification and expansion. Scientific Reports $\mathbf{5}$

Dubos C, Stracke R, Grotewold E, Weisshaar B, Martin C, Lepiniec L (2010) MYB transcription factors in Arabidopsis. Trends in Plant Science 15: 573-581

Elomaa P, Uimari A, Mehto M, Albert VA, Laitinen RAE, Teeri TH (2003) Activation of Anthocyanin Biosynthesis in Gerbera hybrida (Asteraceae) Suggests Conserved Protein-Protein and Protein-Promoter Interactions between the Anciently Diverged Monocots and Eudicots. Plant Physiology 133: 1831-1842

Espley RV, Hellens RP, Putterill J, Stevenson DE, Kutty-Amma S, Allan AC (2007) Red colouration in apple fruit is due to the activity of the MYB transcription factor, MdMYB10. Plant Journal 49: 414-427

Feng S, Wang Y, Yang S, Xu Y, Chen X (2010) Anthocyanin biosynthesis in pears is regulated by a R2R3-MYB transcription factor PyMYB10. Planta 232: 245-255

Fuda NJ, Ardehali MB, Lis JT (2009) Defining mechanisms that regulate RNA polymerase II transcription in vivo. Nature 461: 186192

Gao JJ, Shen XF, Zhang Z, Peng RH, Xiong AS, Xu J, Zhu B, Zheng JL, Yao QH (2011) The myb transcription factor MdMYB6 suppresses anthocyanin biosynthesis in transgenic Arabidopsis. Plant Cell, Tissue and Organ Culture 106: 235-242

Gonzalez A, Zhao M, Leavitt JM, Lloyd AM (2008) Regulation of the anthocyanin biosynthetic pathway by the TTG1/bHLH/Myb transcriptional complex in Arabidopsis seedlings. Plant Journal 53: 814-827

Heppel SC, Jaffé FW, Takos AM, Schellmann S, Rausch T, Walker AR, Bogs J (2013) Identification of key amino acids for the evolution of promoter target specificity of anthocyanin and proanthocyanidin regulating MYB factors. Plant Molecular Biology 82: 457-471

Jin H, Cominelli E, Bailey P, Parr A, Mehrtens F, Jones J, Tonelli C, Weisshaar B, Martin C (2000) Trancriptional repression by AtMYB4 controls production of UV-protecting sunscreens in Arabidopsis. EMBO Journal 19: 6150-6161

Jun JH, Liu C, Xiao X, Dixon RA (2015) The transcriptional repressor MYB2 regulates both spatial and temporal patterns of proanthocyandin and anthocyanin pigmentation in Medicago truncatula. The Plant Cell 27: 2860-2879

Jung CS, Griffiths HM, De Jong DM, Cheng S, Bodis M, Kim TS, De Jong WS (2009) The potato developer (D) locus encodes an R2R3 MYB transcription factor that regulates expression of multiple anthocyanin structural genes in tuber skin. Theoretical and Applied Genetics 120: 45-57

Kagale S, Rozwadowski K (2011) EAR motif-mediated transcriptional repression in plants: An underlying mechanism for epigenetic regulation of gene expression. Epigenetics 6: 141-146

Kiferle C, Fantini E, Bassolino L, Povero G, Spelt C, Buti S, Giuliano G, Quattrocchio F, Koes R, Perata P, Gonzali S (2015) 
bioRxiv preprint doi: https://doi.org/10.1101/2021.08.24.457473; this version posted September 13, 2021. The copyright holder for this preprint (which was not certified by peer review) is the author/funder, who has granted bioRxiv a license to display the preprint in perpetuity. It is made available under aCC-BY-NC-ND 4.0 International license.

Tomato R2R3-MYB Proteins SIANT1 and SlAN2: Same Protein Activity, Different Roles. Plos One 10

Kim S, Park J, Yeom SI, Kim YM, Seo E, Kim KT, Kim MS, Lee JM, Cheong K, Shin HS, Kim SB, Han K, Lee J, Park M, Lee HA, Lee HY, Lee Y, Oh S, Lee JH, Choi E, Choi E, Lee SE, Jeon J, Kim H, Choi G, Song H, Lee JK, Lee SC, Kwon JK, Lee HY, Koo N, Hong Y, Kim RW, Kang WH, Huh JH, Kang BC, Yang TJ, Lee YH, Bennetzen JL, Choi D (2017) New reference genome sequences of hot pepper reveal the massive evolution of plant disease-resistance genes by retroduplication. Genome Biology 18

Kim S, Park M, Yeom SI, Kim YM, Lee JM, Lee HA, Seo E, Choi J, Cheong K, Kim KT, Jung K, Lee GW, Oh SK, Bae C, Kim SB, Lee HY, Kim SY, Kim MS, Kang BC, Jo YD, Yang HB, Jeong HJ, Kang WH, Kwon JK, Shin C, Lim JY, Park JH, Huh JH, Kim JS, Kim BD, Cohen O, Paran I, Suh MC, Lee SB, Kim YK, Shin Y, Noh SJ, Park J, Seo YS, Kwon SY, Kim HA, Park JM, Kim HJ, Choi SB, Bosland PW, Reeves G, Jo SH, Lee BW, Cho HT, Choi HS, Lee MS, Yu Y, Do Choi Y, Park BS, Van Deynze A, Ashrafi H, Hill T, Kim WT, Pai HS, Ahn HK, Yeam I, Giovannoni JJ, Rose JKC, Sørensen I, Lee SJ, Kim RW, Choi IY, Choi BS, Lim JS, Lee YH, Choi D (2014) Genome sequence of the hot pepper provides insights into the evolution of pungency in Capsicum species. Nature Genetics 46: 270-278

Kranz HD, Denekamp M, Greco R, Jin H, Leyva A, Meissner RC, Petroni K, Urzainqui A, Bevan M, Martin C, Smeekens S, Tonelli C, Paz-Ares J, Weisshaar B (1998) Towards functional characterisation of the members of the R2R3-MYB gene family from Arabidopsis thaliana. Plant Journal 16: 263-276

LaFountain AM, Yuan YW (2021) Repressors of anthocyanin biosynthesis. New Phytologist 231: 933-949

Li Y, Lin-Wang K, Liu Z, Allan AC, Qin S, Zhang J, Liu Y (2020) Genome-wide analysis and expression profiles of the StR2R3MYB transcription factor superfamily in potato (Solanum tuberosum L.). International Journal of Biological Macromolecules 148: 817-832

Li Z, Peng R, Tian Y, Han H, Xu J, Yao Q (2016) Genome-wide identification and analysis of the MYB transcription factor superfamily in solanum lycopersicum. Plant and Cell Physiology 57: 1657-1677

Lin-Wang K, McGhie TK, Wang M, Liu Y, Warren B, Storey R, Espley RV, Allan AC (2014) Engineering the anthocyanin regulatory complex of strawberry (Fragaria vesca). Frontiers in Plant Science $\mathbf{5}$

Liu Y, Lv J, Liu Z, Wang J, Yang B, Chen W, Ou L, Dai X, Zhang Z, Zou X (2020) Integrative analysis of metabolome and transcriptome reveals the mechanism of color formation in pepper fruit (Capsicum annuum L.). Food Chemistry 306: 125629

Liu Y, Tikunov Y, Schouten RE, Marcelis LFM, Visser RGF, Bovy A (2018) Anthocyanin Biosynthesis and Degradation Mechanisms in Solanaceous Vegetables: A Review. Frontiers in Chemistry 6

Liu Y, Wang L, Zhang J, Yu B, Wang J, Wang D (2017) The MYB transcription factor StMYBA1 from potato requires light to activate anthocyanin biosynthesis in transgenic tobacco. Journal of Plant Biology 60: 93-101

Liu YH, Lin-Wang K, Espley RV, Wang L, Yang HY, Yu B, Dare A, Varkonyi-Gasic E, Wang J, Zhang JL, Wang D, Allan AC (2016) Functional diversification of the potato R2R3 MYB anthocyanin activators AN1, MYBA1, and MYB113 and their interaction with basic helix-loop-helix cofactors. Journal of Experimental Botany 67: 2159-2176

Livak KJ, Schmittgen TD (2001) Analysis of relative gene expression data using real-time quantitative PCR and the 2- $\Delta \Delta C \mathrm{CT}$ method. Methods 25: 402-408

Ma D, Constabel CP (2019) MYB Repressors as Regulators of Phenylpropanoid Metabolism in Plants. Trends in Plant Science 24: $275-289$

Mano H, Ogasawara F, Sato K, Higo H, Minobe Y (2007) Isolation of a regulatory gene of anthocyanin biosynthesis in tuberous roots of purple-fleshed sweet potato. Plant Physiology 143: 1252-1268

Mathews H, Clendennen SK, Caldwell CG, Liu XL, Connors K, Matheis N, Schuster DK, Menasco DJ, Wagoner W, Lightner J, Wagner RD (2003) Activation tagging in tomato identifies a transcriptional regulator of anthocyanin biosynthesis, modification, and transport. Plant Cell 15: 1689-1703

Mur LA (1995) Characterization of members of the MYB gene family of transcription factors from Petunia Hybrida. [S.1. : s.n.]

Nakatsuka T, Haruta KS, Pitaksutheepong C, Abe Y, Kakizaki Y, Yamamoto K, Shimada N, Yamamura S, Nishihara M (2008) Identification and characterization of R2R3-MYB and bHLH transcription factors regulating anthocyanin biosynthesis in gentian flowers. Plant and Cell Physiology 49: 1818-1829

Ogata K, Hojo H, Aimoto S, Nakai T, Nakamura H, Sarai A, Ishii S, Nishimura Y (1992) Solution structure of a DNA-binding unit of Myb: A helix-turn-helix-related motif with conserved tryptophans forming a hydrophobic core. Proceedings of the National Academy of Sciences of the United States of America 89: 6428-6432

Park JS, Kim JB, Cho KJ, Cheon CI, Sung MK, Choung MG, Roh KH (2008) Arabidopsis R2R3-MYB transcription factor AtMYB60 functions as a transcriptional repressor of anthocyanin biosynthesis in lettuce (Lactuca sativa). Plant Cell Rep 27: 985-994

Pattanaik S, Kong Q, Zaitlin D, Werkman JR, Xie CH, Patra B, Yuan L (2010) Isolation and functional characterization of a floral tissue-specific R2R3 MYB regulator from tobacco. Planta 231: 1061-1076

Peel GJ, Pang Y, Modolo LV, Dixon RA (2009) The LAP1 MYB transcription factor orchestrates anthocyanidin biosynthesis and glycosylation in Medicago. Plant Journal 59: 136-149

Perez-Diaz JR, Perez-Diaz J, Madrid-Espinoza J, Gonzalez-Villanueva E, Moreno Y, Ruiz-Lara S (2016) New member of the R2R3-MYB transcription factors family in grapevine suppresses the anthocyanin accumulation in the flowers of transgenic tobacco. Plant Molecular Biology 90: 63-76

Qin C, Yu C, Shen Y, Fang X, Chen L, Min J, Cheng J, Zhao S, Xu M, Luo Y, Yang Y, Wu Z, Mao L, Wu H, Changying LH, Zhou H, Lin H, González-Morales S, Trejo-Saavedra DL, Tian H, Tang X, Zhao M, Huang Z, Zhou A, Yao X, Cui J, Li W, Chen Z, Feng Y, Niu Y, Bi S, Yang X, Li W, Cai H, Luo X, Montes-Hernández S, Leyva-González MA, Xiong Z, He X, Bai L, Tan S, Tang X, Liu D, Liu J, Zhang S, Chen M, Zhang L, Zhang L, Zhang Y, Liao W, Zhang Y, Wang M, Lv X, Wen B, Liu H, Luan H, Zhang Y, Yang S, Wang X, Xu J, Li X, Li S, Wang J, Palloix A, Bosland PW, Li Y, Krogh A, Rivera-Bustamante RF, Herrera-Estrella L, Yin Y, Yu J, Hu K, Zhang Z (2014) Whole-genome sequencing of cultivated and wild peppers provides insights into Capsicum domestication and specialization. Proceedings of the National 
Academy of Sciences of the United States of America 111: 5135-5140

Quattrocchio F, Wing J, van der Woude K, Souer E, de Vetten N, Mol J, Koes R (1999) Molecular analysis of the anthocyanin2 gene of petunia and its role in the evolution of flower color. Plant Cell 11: 1433-1444

Salvatierra A, Pimentel P, Moya-León MA, Herrera R (2013) Increased accumulation of anthocyanins in Fragaria chiloensis fruits by transient suppression of FcMYB1 gene. Phytochemistry 90: 25-36

Sapir M, Oren-Shamir M, Ovadia R, Reuveni M, Evenor D, Tadmor Y, Nahon S, Shlomo H, Chen L, Meir A, Levin I (2008) Molecular aspects of Anthocyanin fruit tomato in relation to high pigment-1. J Hered 99: 292-303

Schwinn K, Venail J, Shang Y, Mackay S, Alm V, Butelli E, Oyama R, Bailey P, Davies K, Martin C (2006) A small family of MYB-regulatory genes controls floral pigmentation intensity and patterning in the Genus antirrhinum. Plant Cell 18: 831851

Shen X, Zhao K, Liu L, Zhang K, Yuan H, Liao X, Wang Q, Guo X, Li F, Li T (2014) A role for PacMYBA in ABA-regulated anthocyanin biosynthesis in red-colored sweet cherry cv. Hong Deng (Prunus avium L.). Plant and Cell Physiology 55: 862880

Stracke R, Ishihara H, Huep G, Barsch A, Mehrtens F, Niehaus K, Weisshaar B (2007) Differential regulation of closely related R2R3-MYB transcription factors controls flavonol accumulation in different parts of the Arabidopsis thaliana seedling. Plant Journal 50: 660-677

Stracke R, Werber M, Weisshaar B (2001) The R2R3-MYB gene family in Arabidopsis thaliana. Current Opinion in Plant Biology 4: $447-456$

Takos AM, Jaffé FW, Jacob SR, Bogs J, Robinson SP, Walker AR (2006) Light-induced expression of a MYB gene regulates anthocyanin biosynthesis in red apples. Plant Physiology 142: 1216-1232

Vimolmangkang S, Han Y, Wei G, Korban SS (2013) An apple MYB transcription factor, MdMYB3, is involved in regulation of anthocyanin biosynthesis and flower development. BMC Plant Biology 13

Voorrips RE (2002) Mapchart: Software for the graphical presentation of linkage maps and QTLs. Journal of Heredity 93: 77-78

Wang J, Liu Y, Tang B, Dai X, Xie L, Liu F, Zou X (2020) Genome-Wide Identification and Capsaicinoid Biosynthesis-Related Expression Analysis of the R2R3-MYB Gene Family in Capsicum annuum L. Frontiers in Genetics 11

Wang S, Chen Z, Ji T, Di Q, Li L, Wang X, Wei M, Shi Q, Li Y, Gong B, Yang F (2016) Genome-wide identification and characterization of the R2R3MYB transcription factor superfamily in eggplant (Solanum melongena L.). Agri Gene 2: 38-52

Wang Y, Tang H, Debarry JD, Tan X, Li J, Wang X, Lee TH, Jin H, Marler B, Guo H, Kissinger JC, Paterson AH (2012) MCScanX: A toolkit for detection and evolutionary analysis of gene synteny and collinearity. Nucleic Acids Research 40: e49

Xu WJ, Dubos C, Lepiniec L (2015) Transcriptional control of flavonoid biosynthesis by MYB-bHLH-WDR complexes. Trends in Plant Science 20: 176-185

Yanhui C, Xiaoyuan Y, Kun H, Meihua L, Jigang L, Zhaofeng G, Zhiqiang L, Yunfei Z, Xiaoxiao W, Xiaoming Q, Yunping S, Li Z, Xiaohui D, Jingchu L, Xing-Wang D, Zhangliang C, Hongya G, Li-Jia Q (2006) The MYB transcription factor superfamily of Arabidopsis: Expression analysis and phylogenetic comparison with the rice MYB family. Plant Molecular Biology 60: 107-124

Zhang Y, Li Y, Li W, Hu Z, Yu X, Tu Y, Zhang M, Huang J, Chen G (2019) Metabolic and molecular analysis of nonuniform anthocyanin pigmentation in tomato fruit under high light. Horticulture Research 6: 56

Zhang Z, Li DW, Jin JH, Yin YX, Zhang HX, Chai WG, Gong ZH (2015) VIGS approach reveals the modulation of anthocyanin biosynthetic genes by CaMYB in chili pepper leaves. Front Plant Sci 6: 500

Zhao P, Li Q, Li J, Wang L, Ren Z (2014) Genome-wide identification and characterization of R2R3MYB family in Solanum lycopersicum. Molecular Genetics and Genomics 289: 1183-1207 


\section{Tables}

Table 1. Assembly descriptions and sources for three genomes used to characterize R2R3-MYB diversity in Capsicum spp.

Table 2. Ka-Ks calculation of each pair of syntenic R2R3-MYB paralogs within Capsicum annuum, Capsicum baccatum and Capsicum chinense, respectively.

Table 3. Plant R2R3-MYB family genes involved in anthocyanin biosynthesis.

Table 4. Capsicum spp. R2R3-MYB repressors with conserved repressor motifs. 
bioRxiv preprint doi: https://doi.org/10.1101/2021.08.24.457473; this version posted September 13, 2021. The copyright holder for this preprint (which was not certified by peer review) is the author/funder, who has granted bioRxiv a license to display the preprint in perpetuity. It is made available under aCC-BY-NC-ND 4.0 International license.

Table 1. Assembly descriptions and sources for three genomes used to characterize R2R3-MYB diversity in Capsicum spp.

\begin{tabular}{|c|c|c|c|}
\hline Genome features & Capsicum annuum $^{l}$ & Capsicum baccatum $^{2}$ & Capsicum chinense $^{2}$ \\
\hline Assembled genome size $(\mathrm{Gb})$ & 2.9 & 3.2 & 3.0 \\
\hline Number of Scaffolds & 6478 & 2083 & 1557 \\
\hline Scaffold N50 (Mb) & 1.4 & $2.0 \mathrm{Mb}$ & $3.3 \mathrm{Mb}$ \\
\hline Coverage & $99 X$ & $98 \mathrm{X}$ & $80 \mathrm{X}$ \\
\hline
\end{tabular}

${ }^{1}$ Pepper Zunla 1 Ref_v1.0 (https://www.ncbi.nlm.nih.gov/assembly/GCA_000710875.1);

${ }^{2}$ Kim et al. (2017). 
bioRxiv preprint doi: https://doi.org/10.1101/2021.08.24.457473; this version posted September 13, 2021. The copyright holder for this preprint (which was not certified by peer review) is the author/funder, who has granted bioRxiv a license to display the preprint in perpetuity. It is made available under aCC-BY-NC-ND 4.0 International license.

Table 2. Ka-Ks calculation of each pair of syntenic R2R3-MYB paralogs within Capsicum annuum, Capsicum baccatum and Capsicum chinense, respectively. The minimum block size for collinear analysis is set at 5 in MCSanX for intraspecies analysis.

\begin{tabular}{|c|c|c|c|c|c|c|c|}
\hline Sequence1 & Sequence 2 & $\mathrm{Ka}^{1}$ & $\mathrm{Ks}^{2}$ & $\mathrm{Ka} / \mathrm{Ks}$ & Effective Len $^{3}$ & Average S-sites ${ }^{4}$ & Average N-sites \\
\hline CaMYB12 & CaMYB19 & 0.20 & 0.84 & 0.24 & 858 & 186.67 & 671.33 \\
\hline CaMYB13 & CaMYB20 & 0.13 & 0.63 & 0.20 & 585 & 120.67 & 464.33 \\
\hline CaMYB19 & CaMYB24 & 0.34 & 2.54 & 0.13 & 864 & 190.33 & 673.67 \\
\hline CaMYB16 & CaMYB34 & 0.27 & 1.44 & 0.18 & 783 & 190.42 & 592.58 \\
\hline CaMYB15 & CaMYB35 & 0.46 & 1.56 & 0.29 & 864 & 186.42 & 677.58 \\
\hline CaMYB12 & CaMYB54 & 0.33 & 1.47 & 0.23 & 957 & 209.58 & 747.42 \\
\hline CaMYB16 & CaMYB93 & 0.34 & 1.72 & 0.20 & 636 & 145.67 & 490.33 \\
\hline CaMYB26 & CaMYB52 & 0.22 & 0.43 & 0.50 & 867 & 176.58 & 690.42 \\
\hline CaMYB23 & CaMYB91 & 0.37 & 3.55 & 0.11 & 765 & 154.25 & 610.75 \\
\hline CaMYB34 & CaMYB93 & 0.26 & 1.71 & 0.15 & 726 & 162.67 & 563.33 \\
\hline CaMYB51 & CaMYB85 & 0.31 & 0.82 & 0.38 & 858 & 173.83 & 684.17 \\
\hline CaMYB64 & CaMYB79 & 0.15 & 0.80 & 0.19 & 942 & 199.08 & 742.92 \\
\hline CaMYB76 & CaMYB83 & 0.14 & 0.75 & 0.19 & 381 & 79.25 & 301.75 \\
\hline CbMYB106 & CbMYB13 & 0.25 & 1.41 & 0.18 & 867 & 206.17 & 660.83 \\
\hline CbMYB12 & CbMYB29 & 0.44 & 1.91 & 0.23 & 858 & 186.08 & 671.92 \\
\hline CcMYB107 & CcMYB14 & 0.33 & 1.53 & 0.22 & 957 & 208.58 & 748.42 \\
\hline CcMYB12 & CcMYB50 & 0.33 & 0.83 & 0.39 & 807 & 162.25 & 644.75 \\
\hline CcMYB14 & CcMYB22 & 0.20 & 0.89 & 0.23 & 858 & 186.67 & 671.33 \\
\hline CcMYB16 & CcMYB39 & 0.25 & 1.42 & 0.17 & 855 & 203.17 & 651.83 \\
\hline CcMYB19 & CcMYB38 & 0.40 & 1.70 & 0.24 & 855 & 185.08 & 669.92 \\
\hline CcMYB31 & CcMYB56 & 0.23 & 0.44 & 0.53 & 882 & 179.67 & 702.33 \\
\hline CcMYB40 & CcMYB103 & 0.51 & 2.17 & 0.24 & 615 & 140.25 & 474.75 \\
\hline CcMYB39 & CcMYB103 & 0.26 & 1.70 & 0.15 & 726 & 163.83 & 562.17 \\
\hline CcMYB41 & CcMYB101 & 0.26 & 0.91 & 0.29 & 849 & 170.25 & 678.75 \\
\hline
\end{tabular}

\footnotetext{
${ }^{1} \mathrm{Ka}$, non-synonymous substitution rate;

${ }^{2} \mathrm{Ks}$, synonymous substitution rate;

${ }^{3}$ Effective Len: effctive length of compared sequences;

${ }^{4}$ S-site, number of synonymous site;

${ }^{5} \mathrm{~N}$-site, number of non-synonymous sites.
} 
bioRxiv preprint doi: https://doi.org/10.1101/2021.08.24.457473; this version posted September $13,2021$. The copyright holder for this preprint (which was not certified by peer review) is the author/funder, who has granted bioRxiv a license to display the preprint in perpetuity. It is made available under aCC-BY-NC-ND 4.0 International license.

Table 3. Plant R2R3-MYB family genes involved in anthocyanin biosynthesis.

\begin{tabular}{|c|c|c|c|c|}
\hline Gene name & Gene ID & Species & $\begin{array}{l}\text { Function } \\
\text { (activator+/repressor-) }\end{array}$ & References \\
\hline AmROSEA1 & DQ275529 & Anitirrhinum majus & + & Schwinn et al. (2006) \\
\hline AmROSEA2 & DQ275530 & Anitirrhinum majus & + & Schwinn et al. (2006) \\
\hline AmVenosa & DQ275531 & Anitirrhinum majus & + & Schwinn et al. (2006) \\
\hline AtPAP1/AtMYB75 & AT1G56650 & Arabidopsis thaliana & + & Borevitz et al. (2000) \\
\hline AtPAP2/AtMYB90 & AT1G66390 & Arabidopsis thaliana & + & Borevitz et al. (2000) \\
\hline AtPAP3/AtMYB113 & AT1G66370 & Arabidopsis thaliana & + & Gonzalez et al. (2008) \\
\hline AtPAP4/AtMYB114 & AT1G66380 & Arabidopsis thaliana & + & $\begin{array}{c}\text { Gonzalez et al. (2008); Heppel } \\
\text { et al. (2013) }\end{array}$ \\
\hline AtMYB60 & AT1G08810 & Arabidopsis thaliana & - & $\begin{array}{l}\text { Kranz et al. (1998); Park et al. } \\
\text { (2008) }\end{array}$ \\
\hline CaMYBA & AJ608992 & Capsicum annuum & + & $\begin{array}{c}\text { Borovsky et al. (2004); } \\
\text { Aguilar-Barragán and Ochoa- } \\
\text { Alejo (2014) }\end{array}$ \\
\hline FaMYB1 & MN689833 & Fragaria $x$ ananassa & - & Aharoni et al. (2001) \\
\hline FaMYB10 & EU155162 & Fragaria vesca & + & Lin-Wang et al. (2014) \\
\hline FcMYB1 & GQ867222 & Fragaria chiloensis & - & Salvatierra et al. (2013) \\
\hline GhMYB10 & AJ554700 & Gerbera hybrida & + & Elomaa et al. (2003) \\
\hline GtMYB3 & AB289445 & Gentiana triflora & + & Nakatsuka et al. (2008) \\
\hline IbMYB1 & AB258984 & Ipomoea batatas & + & Mano et al. (2007) \\
\hline MdMYB1 & DQ886414 & Malus domestica Borkh. & + & Takos et al. (2006) \\
\hline MdMYB3 & JN544704 & Malus $\times$ domestica & + & Vimolmangkang et al. (2013) \\
\hline MdMYB6 & DQ074461 & Malus $\times$ domestica & - & Gao et al. (2011) \\
\hline MdMYB10 & EU518249 & Malus $\times$ domestica & + & Espley et al. (2007) \\
\hline MtLAP1 & FJ199998 & Medicago truncatula & + & $\begin{array}{l}\text { Peel et al. (2009); Bond et al. } \\
\text { (2016) }\end{array}$ \\
\hline MtMYB2 & AES99346 & Medicago truncatula & - & Jun et al. (2015) \\
\hline NtAN2 & FJ472647 & Nicotiana tabacum & + & Pattanaik et al. (2010) \\
\hline PacMYBA & JN166079 & Prunus avium $L$ & + & Shen et al. (2014) \\
\hline PhAN2 & AAF66727 & Petunia hybrida & + & Quattrocchio et al. (1999) \\
\hline PhDPL & HQ116169 & Petunia hybrida & + & Albert et al. (2011) \\
\hline PhMYB27 & KF985023 & Petunia hybrida & - & $\begin{array}{l}\text { Mur (1995); Albert et al. } \\
\text { (2011) }\end{array}$ \\
\hline PhPHZ & HQ116170 & Petunia hybrida & + & Albert et al. (2011) \\
\hline
\end{tabular}


bioRxiv preprint doi: https://doi.org/10.1101/2021.08.24.457473; this version posted September 13, 2021. The copyright holder for this preprint (which was not certified by peer review) is the author/funder, who has granted bioRxiv a license to display the preprint in perpetuity. It is made available under aCC-BY-NC-ND 4.0 International license.

\begin{tabular}{|c|c|c|c|c|}
\hline PyMYB10 & KF387520 & Pyrus pyrifolia & + & Feng et al. (2010) \\
\hline SlANT1 $1^{\mathrm{AC}} / \mathrm{LeANT} 1$ & AY348870 & $\begin{array}{l}\text { Solanum lycopersicum } \mathrm{cv} \text {. } \\
\text { Ailsa Craig }\end{array}$ & + & Mathews et al. (2003) \\
\hline SIANT1 $1^{\text {Aft }}$ & $\mathrm{ABO} 26065$ & $\begin{array}{l}\text { Solanum lycopersicum.L } \\
\text { accession LA1996 }\end{array}$ & + & Sapir et al. (2008) \\
\hline SlAN2 & FJ705320 & Solanum lycopersicum.L & + & Kiferle et al. (2015) \\
\hline \multirow[t]{4}{*}{ SIMYBL2 } & \multirow[t]{4}{*}{ XM_004239350 } & The Pro35S:BrTT8 & \multirow[t]{4}{*}{-} & \multirow[t]{4}{*}{ Zhang et al. (2019) } \\
\hline & & transgenic & & \\
\hline & & lycopersicum Mill. $\quad c v$ & & \\
\hline & & Ailsa Craig, $A C$ & & \\
\hline StAN1 & DQ917781 & Solanum tuberosum L. & + & Jung et al. (2009) \\
\hline StAN2 & AY841131 & Solanum tuberosum L. & + & Jung et al. (2009) \\
\hline StMYBA1 & KP317177 & Solanum tuberosum L. & + & $\begin{array}{l}\text { Liu et al. (2016); Liu et al. } \\
\text { (2017) }\end{array}$ \\
\hline VvMYB5b & AY899404 & Vitis vinifera & + & $\begin{array}{c}\text { Deluc et al. (2008); Cavallini } \\
\text { et al. (2014) }\end{array}$ \\
\hline
\end{tabular}


bioRxiv preprint doi: https://doi.org/10.1101/2021.08.24.457473; this version posted September 13,2021 . The copyright holder for this preprint (which was not certified by peer review) is the author/funder, who has granted bioRxiv a license to display the preprint in perpetuity. It is made available under aCC-BY-NC-ND 4.0 International license.

Table 4. Capsicum spp. R2R3-MYB repressors with conserved repressor motifs.

\begin{tabular}{|c|c|c|}
\hline Repression motif & EAR (LxLxL, DLNxxP) motif & LxLxPP motif \\
\hline Capsicum annuиm & $\begin{array}{l}\text { CaMYB5, СaMYB16, СaMYB34, СaMYB45, } \\
\text { CaMYB48, CaMYB50, СaMYB55, СaMYB67, } \\
\text { CaMYB68, СaMYB70, СaMYB72, СaMYB82, } \\
\text { CaMYB91, СaMYB92, СaMYB93, СaMYB101 }\end{array}$ & СаMYB16, СаМYB37 \\
\hline Capsicum baccatum & $\begin{array}{l}\text { CbMYB4, CbMYB13, CbMYB29, CbMYB46, } \\
\text { CbMYB50, CbMYB66, CbMYB67, CbMYB69, } \\
\text { CbMYB76, CbMYB85, CbMYB89, CbMYB92, } \\
\text { CbMYB93, CbMYB94, CbMYB102, CbMYB106 }\end{array}$ & CbMYB13, СbMYB32 \\
\hline Capsicum chinense & 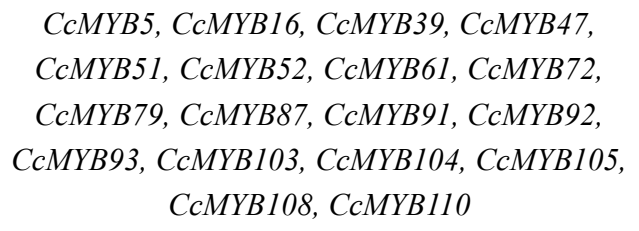 & СсМYВ16, СсМYВ40 \\
\hline
\end{tabular}




\section{Figures}

Figure 1. The conserved motifs of the R2 and R3 domains in Capsicum spp. R2R3-MYB proteins.

Figure 2. Chromosome localization of Capsicum spp. R2R3-MYB family members.

Figure 3 Synteny of the $R 2 R 3-M Y B$ transcription factors in the Capsicum spp. genome.

Figure 4. (A)Phylogenetic tree of R2R3-MYB with repression motif and published anthocyanin-related MYBs.

Figure 5. The gene expression patterns in root, stem, leaf, bud, flower and fruits of Capsicum annuum.

Figure 6. Expression profile of CaMYB101 genes in different tissues and in fruits during different stages obtained using qRT-PCR.

Figure 7. Functional analysis of candidate repressor CaMYB101 of anthocyanin biosynthesis by VIGS.

Figure 8. The relative expression level of anthocyanin biosynthetic genes in the ovaries 
A

$|\mathrm{H}| \mathrm{H}|\mathrm{T}| \mathrm{H} \mid$

\section{Arabidopsis-R2}

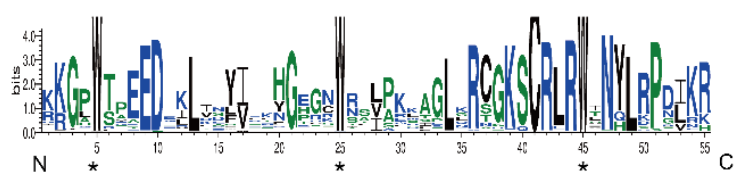

Annuum-R2

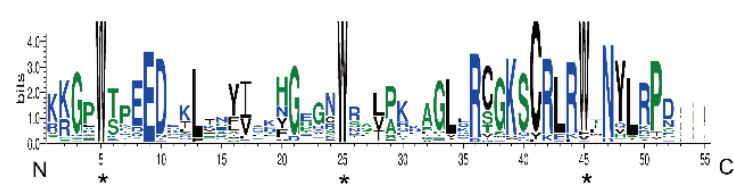

Baccatum-R2

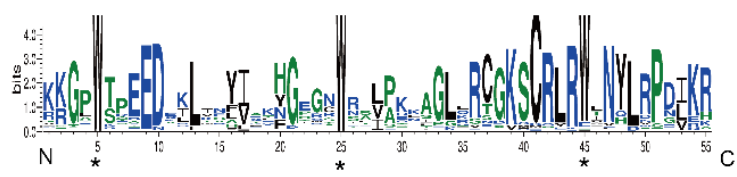

Chinense-R2

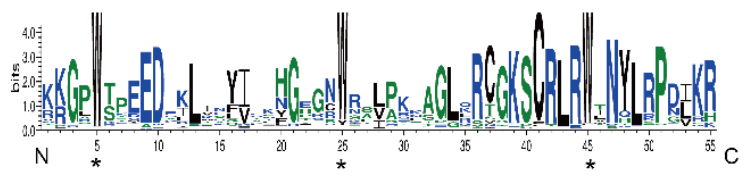

B

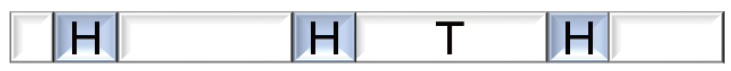

Arabidopsis-R3

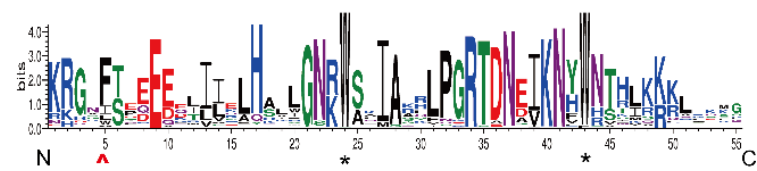

Annuum-R3

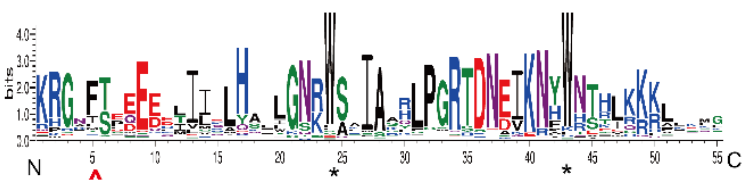

Baccatum-R3

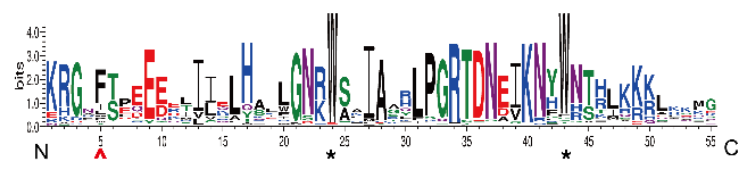

Chinense-R3

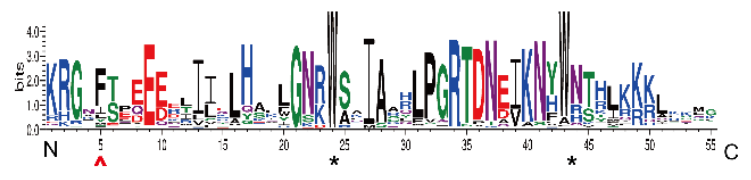

Figure 1. The conserved motifs of the R2 and R3 domains in Capsicum spp. R2R3-MYB proteins. (A) The R2 domain of C. annuum, C. baccatum and C. chinense; (B) the R3 domain of C. annuum, C. baccatum and C. chinense. These sequence logos were determined from the multiple alignment analysis of 108, 106 and 110 R2R3-MYB proteins in $C$. annuum, C. baccatum and C. chinense respectively. Each MYB repeat contains three $\alpha$-helices $(\mathrm{H})$. The second and third helices form a helix-turn-helix architecture (HTH). The bit score shows the information content for each position in the sequence. The conserved tryptophan residues (W) are marked with black asterisks and the replacement of tryptophan in the $\mathrm{R} 3$ repeat are marked by red circumflex accent. 
bioRxiv preprint doi: https://doi.org/10.1101/2021.08.24.457473; this version posted September 13, 2021. The copyright holder for this

preprint (which was not certified by peer review) is the author/funder, who has granted bioRxiv a license to display the preprint in perpetuity. It is made available under aCC-BY-NC-ND 4.0 International license.

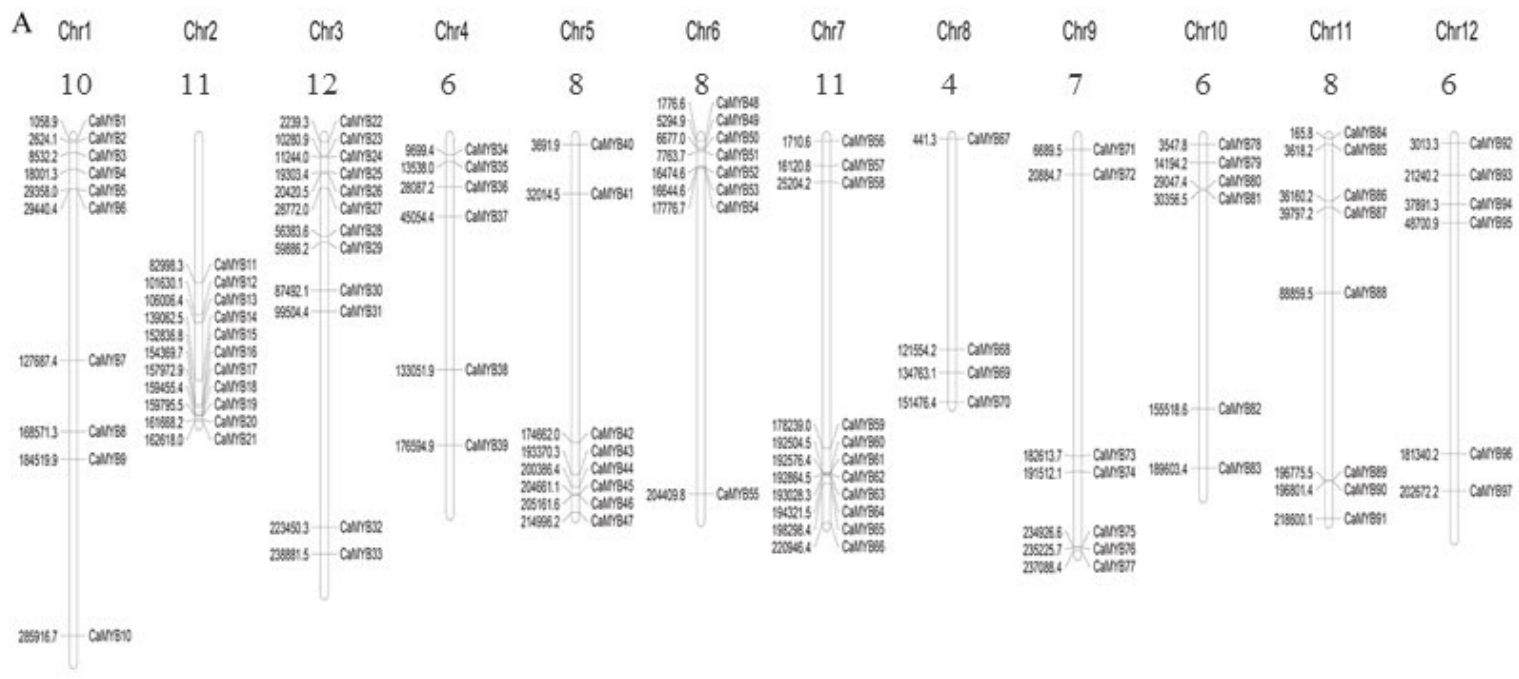

$\begin{array}{llllllllllllll}\text { B Chr1 Chr2 } & \text { Chr3 } & \text { Chr4 } & \text { Chr5 } & \text { Chr6 } & \text { Chr7 } & \text { Chr8 } & \text { Chr9 } & \text { Chr10 } & \text { Chr11 } & \text { Chr12 }\end{array}$

$\begin{array}{llllllllllll}10 & 8 & 10 & 5 & 10 & 10 & 10 & 6 & 5 & 8 & 9 & 6\end{array}$
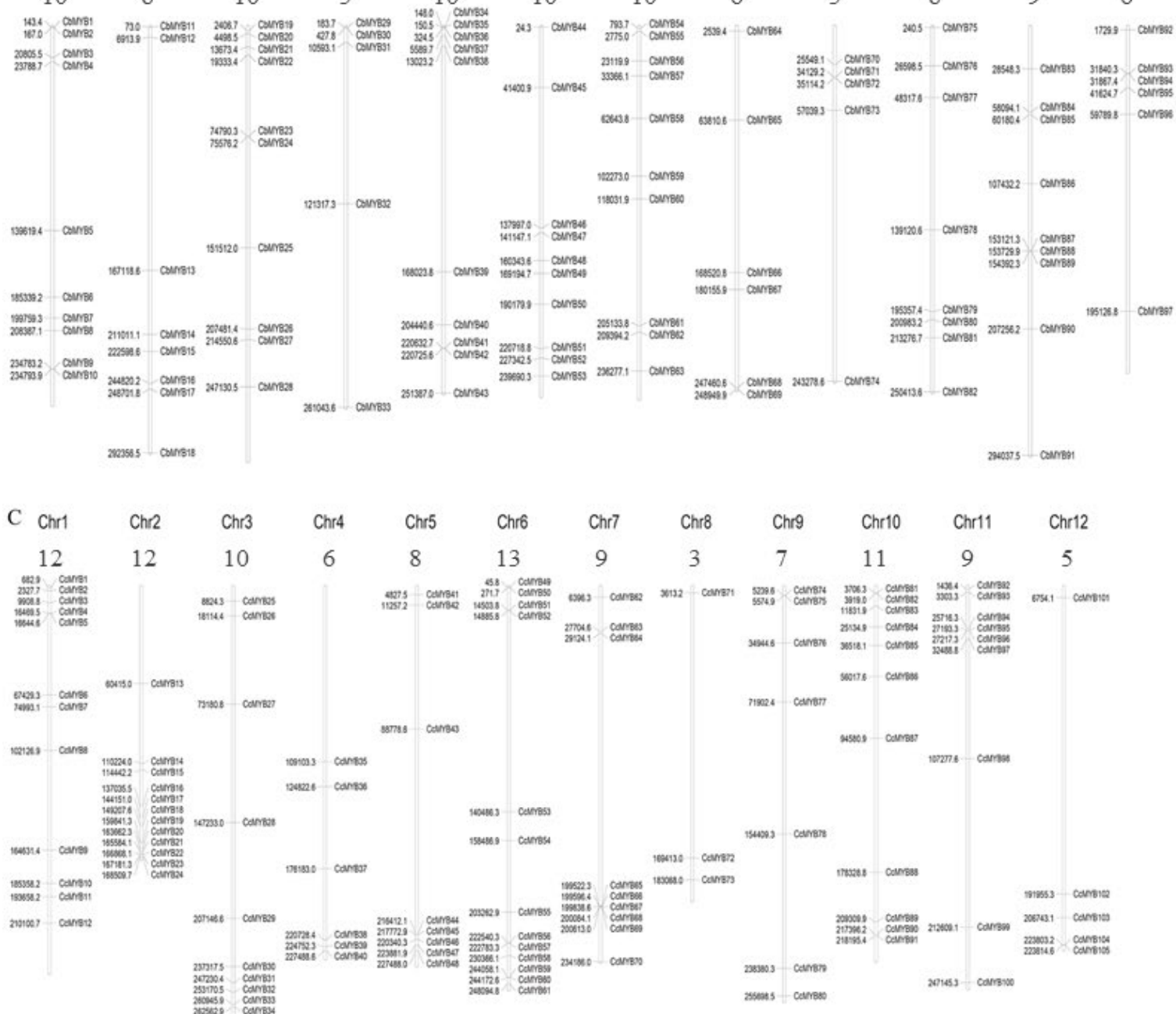

Figure 2. Chromosome localization of Capsicum spp. R2R3-MYB family members. The physical distribution of each R2R3-MYB gene is listed on the chromosomes of (A) Capsicum annuum, (B) Capsicum baccatum and (C) Capsicum chinense. 


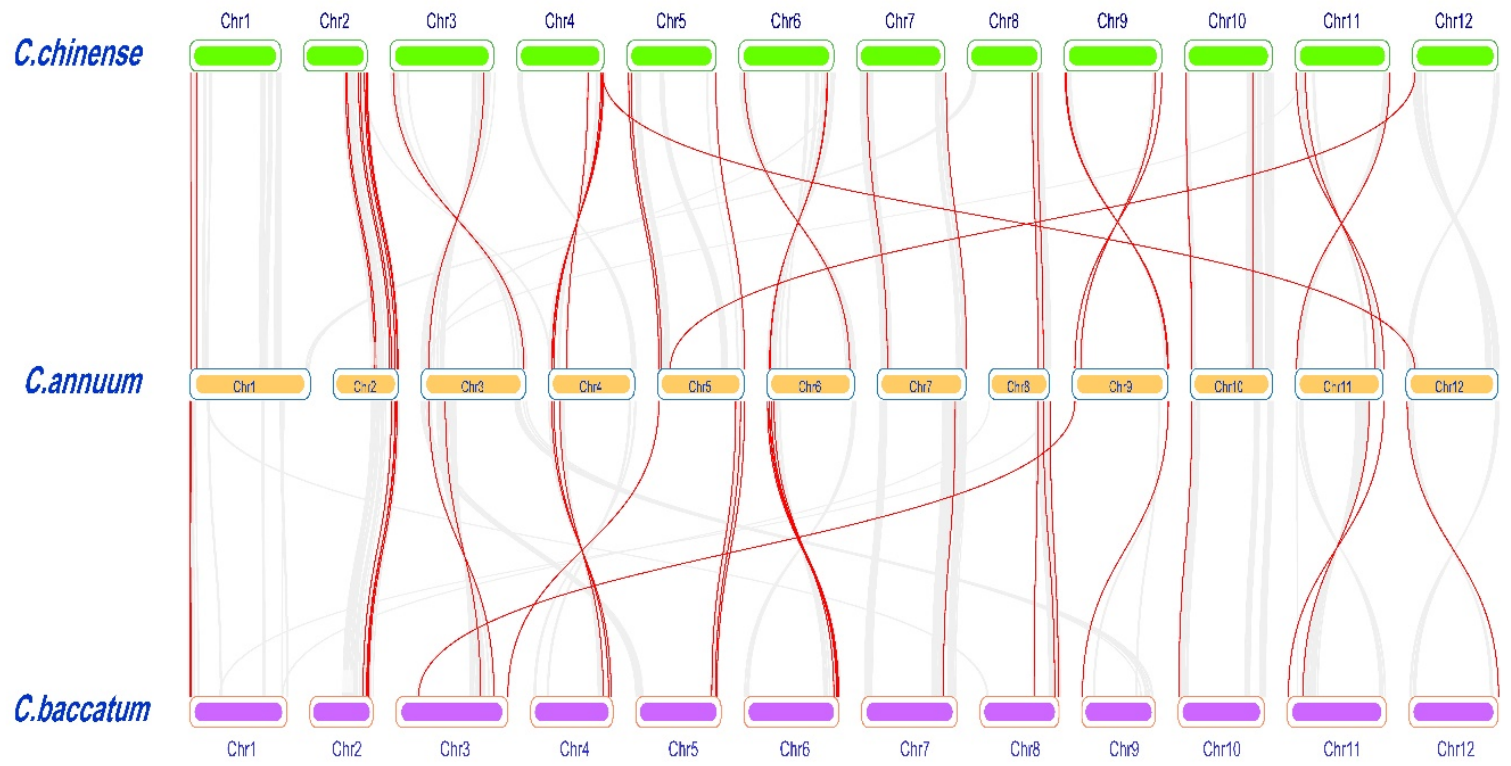

Figure 3 Synteny of the $R 2 R 3-M Y B$ transcription factors across the Capsicum spp. genome. The Capsicum R2R3-MYB were mapped to the corresponding chromosomes of $C$. chinense, $C$. annuum and $C$. baccatum. Those with a syntenic relationship are joined by red lines. The gray lines indicate all syntenic blocks in the Capsicum spp. genome. Specific gene pairs are listed in Supplemental Table S4. The minimum block size for collinear analysis is set at 30 in MCSanX for interspecies analysis. 
bioRxiv preprint doi: https://doi org/10.1101/2021.08 24.457473; this version posted September 13, 2021. The copyright holder for this preprint (which was not certified by peer review) is the author/funder, who has granted bioRxiv a license to display the preprint in perpetuity. It is made available under aCC-BY-NC-ND 4.0 International license.

A

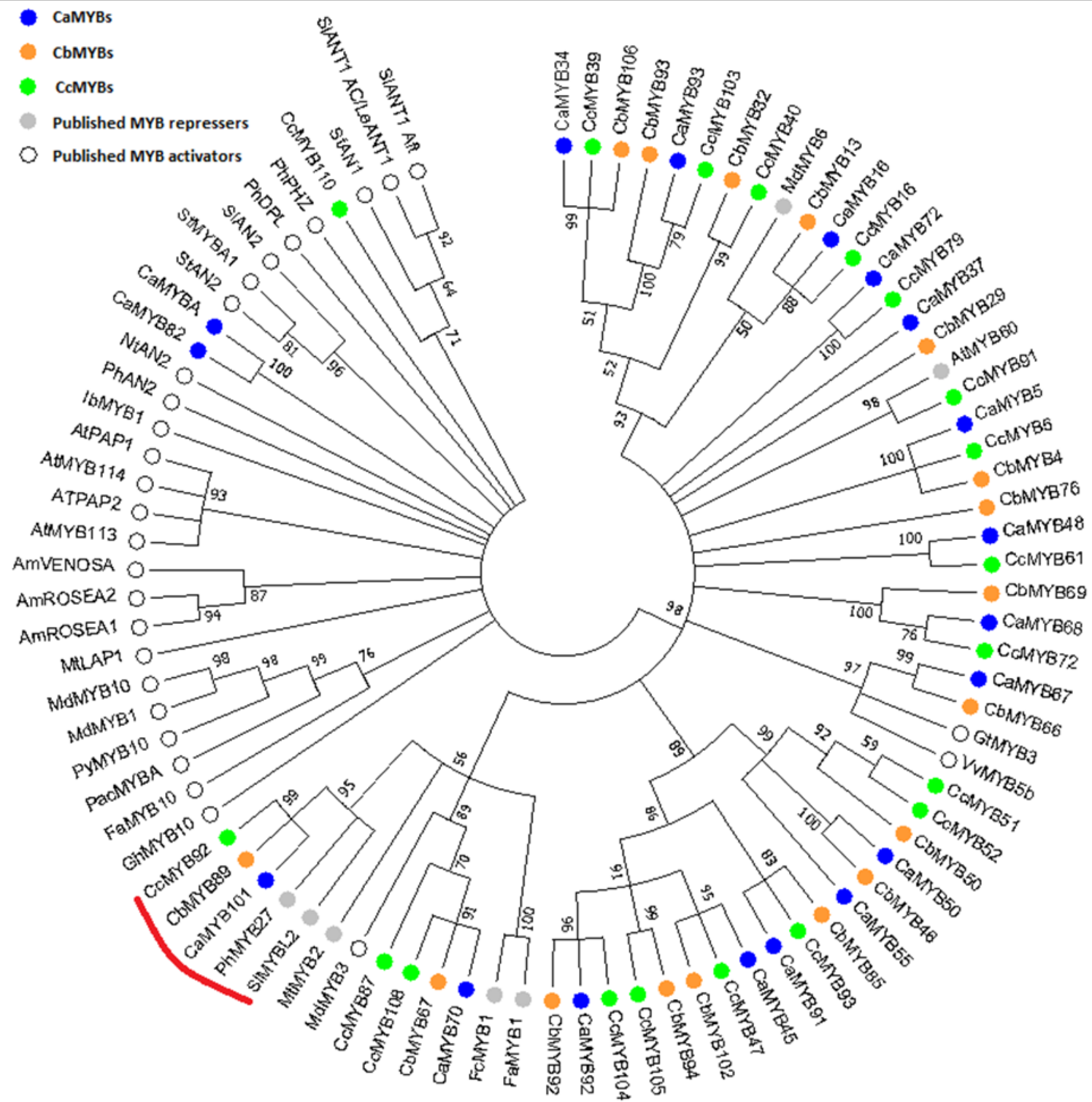

B

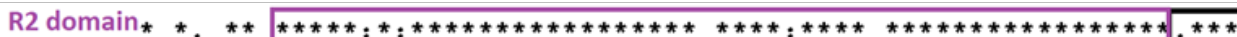
MRKPGCDN KEEMHKGSWSKOEDOKLIDYITKHGEGCWRDLPKAAGLLRCGKSCRL RWMNYT NPNI CCMYB92 MRKPGCDYKEEMHKGSWSKQEDQKLIDYITKH GEGCWRDLPKAA GLLRCGKSCRLRWMNYI NPNI CAMYB101 MSKPGCDNKEEMHKGSWSKQEDQKLIDYITKHGEGCWRDLPKAAGLLRCGKSCRL RWMNYI NPNL SIMYBL2 MRKPCCDNKEEMHK GAWSKQEDQKLIDYITKH GEGCWRNLPKAAGLLRCGKSCRL RWMNYI NPNL PhMYB27 MRKACCDNKEEMHRGAWSKQEDQKLIDYITKHGAGCWRNLPKADGLLRCGKSCRLRWMNYI SPNI

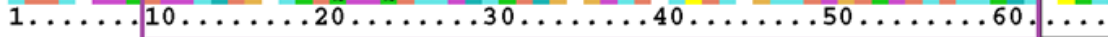
R3 domain bHLH binding domain R3 domain

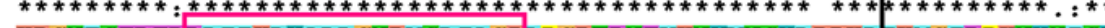
$\begin{array}{ll}\text { KRGNF SEDEDDLIIKLHALLGNRWSL IAGRLPGRTDNEVKNYWNSHLRRKLIKMGIDPKNHNISH } \\ \text { CAMYB101 } & \text { KRGNF SEDEDDLIIKLHALLGNRWSL IAGRLPGRTDNEVKNYWNSHLRRKLIKMGIDPKNHNISH }\end{array}$ SIMYBL2 KRGNFSED EDDLIIKLHALLGNRWSL IAGRLPGRTDNEVKNYWNSHLTRKLIKMGIDPKNHRLSH PhMYB27 KRGNFSEDEEDLIIKLHALLGNRWSL IAGRLPGRTDNEVKNYWNSHLRRKLIKMGIDPKNHRISH

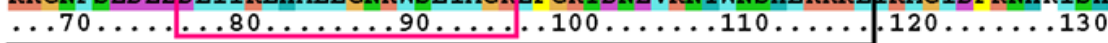

CbMYB89 $* *: * * * * \quad * *: \quad: \quad *: * * * * *$. *******

CCMYB92

YLRIKRLEYFQENSIKSENNAVISDATSSNC-

VTSSLPDLNSLP

YLRIKRLETFQENSIKSENAAVISDATSSNC- - VTSSLPDLNSLP-

YLRIKRLEYFQENGIKSENNAVISDATSSNC----VTSSLFDLNSLP - - - - -

PhMYB27

YLHIKRLELLQENNTRL ENV GVI SDATSSYANKDQQITSSI L DLNL IP- - - - - 187 YLHRKRLEYWSENSSRGTDHEVVSDAGSSCAK---HQPSSLPDLNSPPSIHSSCAQP 187 $\ldots \ldots 140 \ldots \ldots 150 \ldots \ldots 160 \ldots \ldots$ EÁR motif $\ldots \ldots 180 \ldots \ldots$

Figure 4. (A)Phylogenetic tree of R2R3-MYB with repression motif and published anthocyanin-related MYBs. CaMYB82 
bioRxiv preprint doi: https://doi.org/10.1101/2021.08.24.457473; this version posted September 13, 2021. The copyright holder for this preprint (which was not certified by peer review) is the author/funder, who has granted bioRxiv a license to display the preprint in perpetuity. It is made available under aCC-BY-NC-ND 4.0 International license.

and $\mathrm{CaMYB}_{\mathrm{A}}$ is the same gene. The red curve shows the cluster of CaMYB101, CbMYB89 and CcMYB89 with petunia and tomato MYB repressors. The blue, orange and green dots indicate CaMYBs, CbMYBs and CcMYBs, respectively (Table 4). The white and grey dots indicate published MYB activators and MYB repressors (Table 3). (B) Multiple alignment of predicted protein sequences of CaMYB101, CbMYB89, CcMYB92, SIMYBL2 and PhMYB27. The R2, R3 domains, EAR motifs (LxLxL and DLNxxP) and bHLH binding domain is labeled above the alignment. 

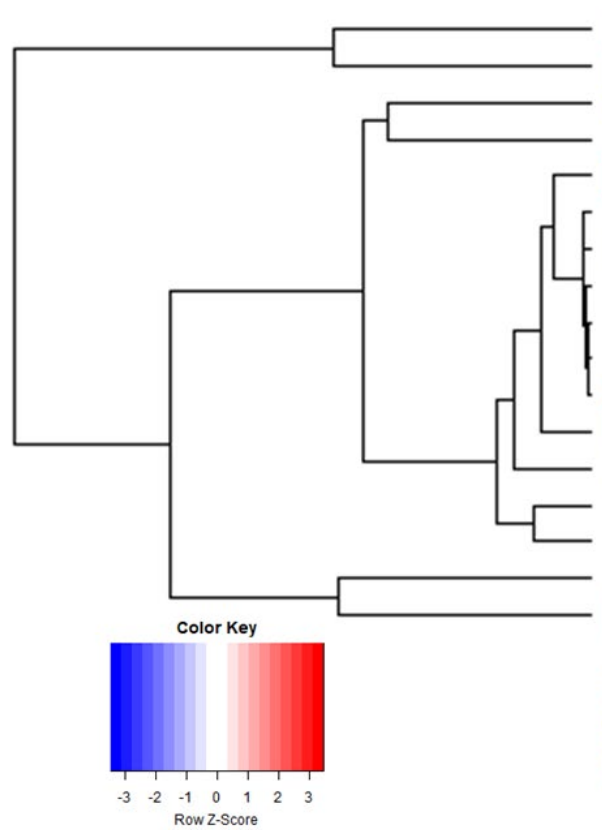
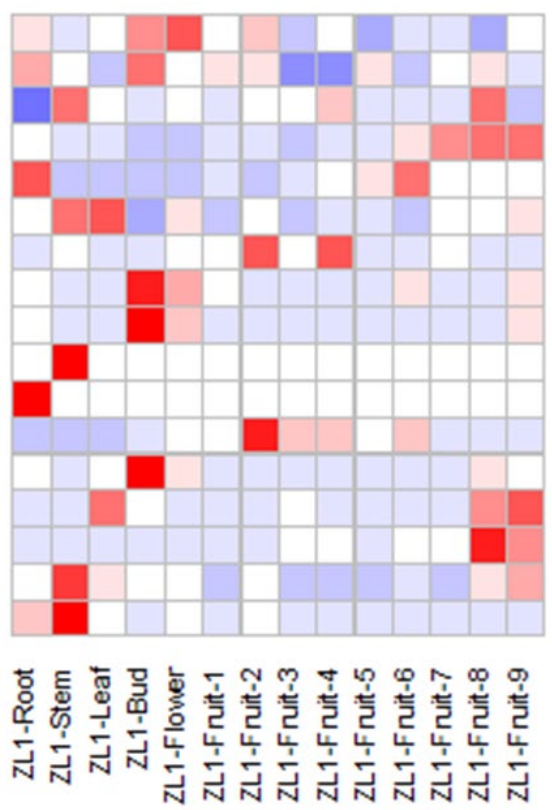

CaMYB16

CaMYB34

CaMYB37

CaMYB45

CaMYB92

CalMYB93

CaMYB101

CalMYB68

CaMYB82

CalMYB55

CalMYB5

CalMYB67

CalMYB48

CalMYB91

CalMYB72

CalMYB70

CalMYB50

Figure 5. The gene expression patterns in root, stem, leaf, bud, flower and fruits of Capsicum annuum cv. Zunla. The color indicates relative gene expression in selected tissues based on rpkm (reads per kb per million mapped reads). Fruit stages 1-3 represent pre-breaker stages $(1-3 \mathrm{~cm}, 3-4 \mathrm{~cm}, 4-5 \mathrm{~cm}$ fruit length; mature green), fruit stages 4-6 represent the breaker stage (when the fruit was turning red) and fruit stages 7-9 represent post-breaker stages (3, 5, and 7 days after breaker). 


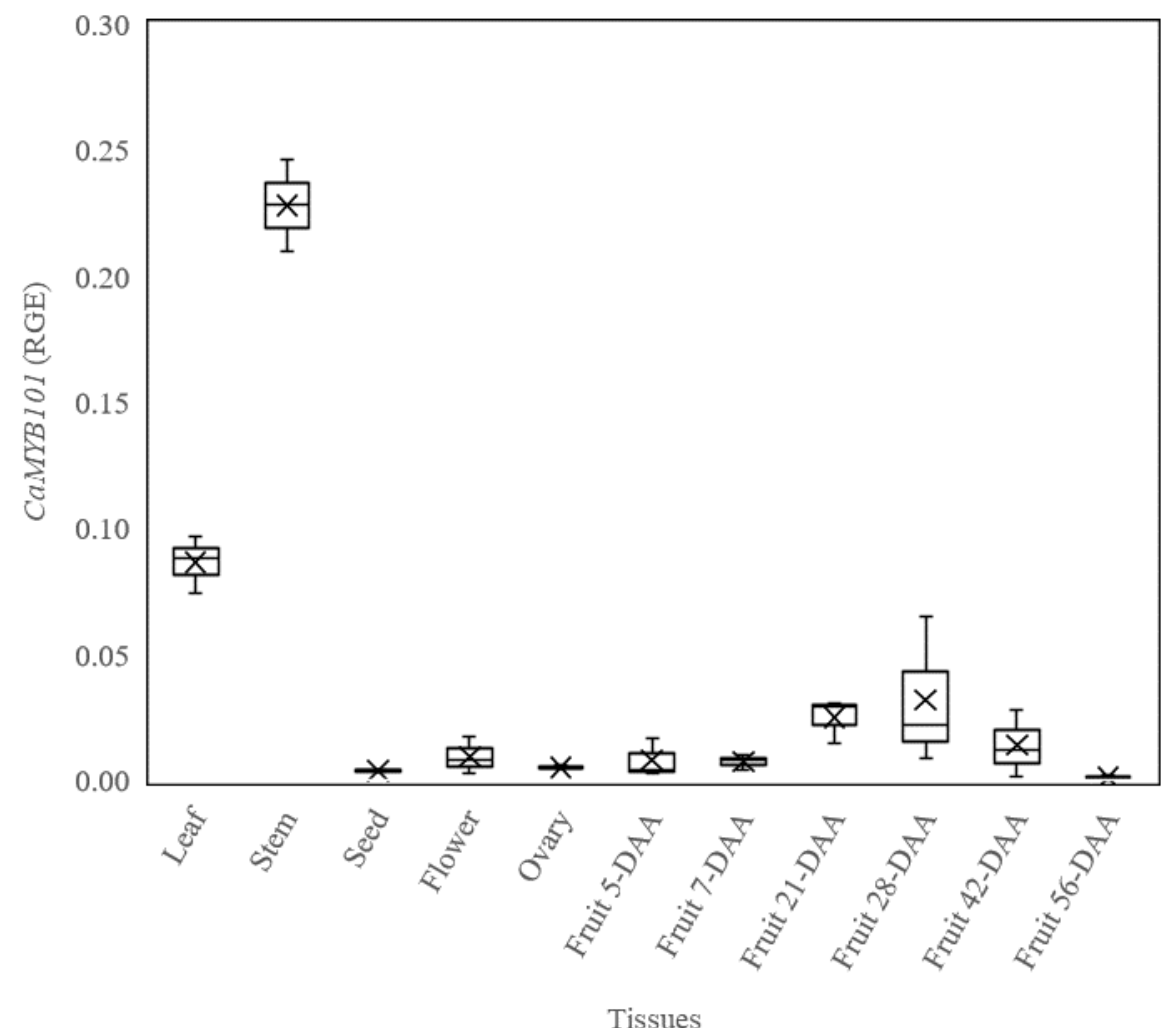

Figure 6. Expression profile of CaMYB101 genes in different tissues and in fruits during different stages obtained via qRT-PCR. A Ubiqutin $(U b)$ gene was used as an internal control. Box plot is generated based on three biological replicates of each tissue $(\mathrm{N}=3)$. Fruit stages refer to Chapter 5 Figure 1. 

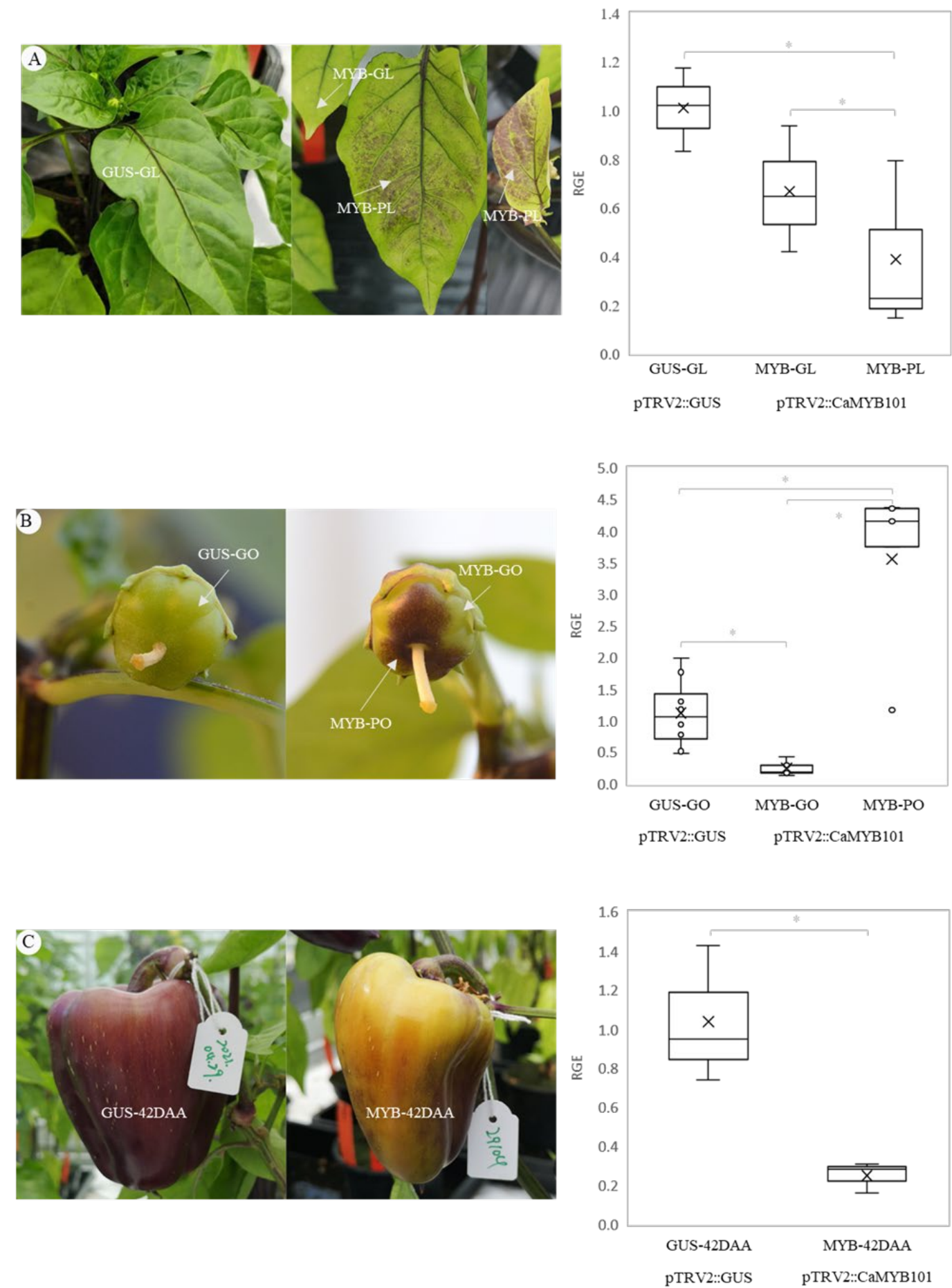

Figure 7. Functional analysis of candidate repressor CaMYB101 of anthocyanin biosynthesis by VIGS. The VIGS experiments were repeated three times with same phenotypes. Data from the third repetition are presented. Phenotyping of pTRV2::CaMYB101 and pTRV2::GUS plants and relative gene expression level of CaMYB101 in (A) leaves $(\mathrm{N}=3)$, (B) ovaries $(\mathrm{N}=5$ ), and $(\mathrm{C})$ fruits (42 DAA; $\mathrm{N}=3$ ). GUS-GL, GUS-GO and GUS-42 DAA represent the pTRV2::GUS green leaves, green ovaries and fruits at 42 DAA, respectively. MYB-GL, MYB-GO represent the green leaves and green parts of ovaries of pTRV2::CaMYB101 silenced plants. MYB-PL and MYB-PO represent the purple leaves and purple parts of ovaries of pTRV2::CaMYB101 silenced plants. MYB-42 DAA represents the pTRV2::CaMYB101 42 DAA fruits. 

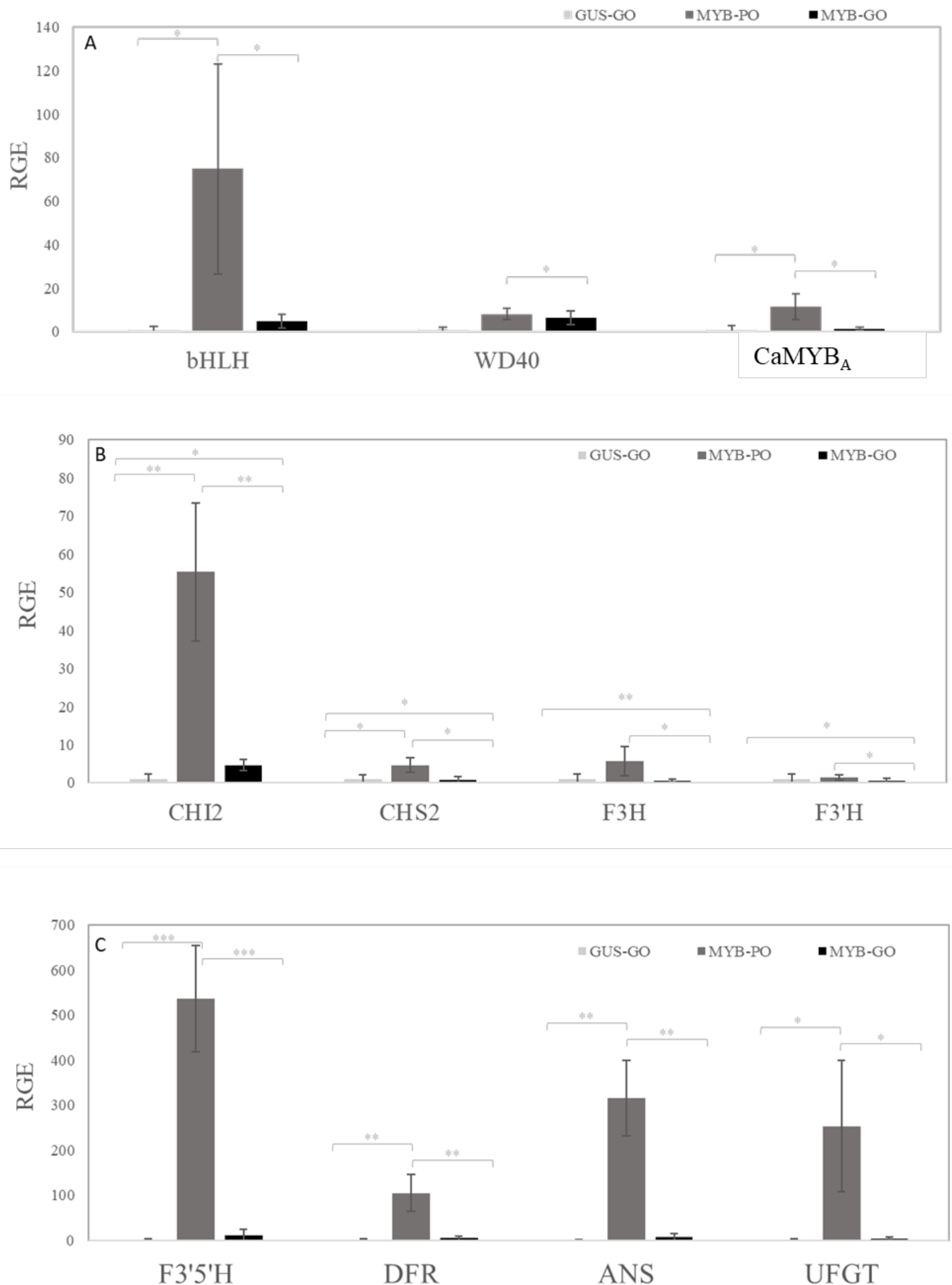

Figure 8. The relative expression level of anthocyanin biosynthetic genes in ovaries (A) CabHLH, CaWD40 and $\mathrm{CaMYB}_{A}$ activator (CaMYB82 in this study and NCBI accession number AJ608992), (B) anthocyanin early biosynthetic genes chalcone synthase 2 (CaCHS2), chalcone isomerase 2 (CaCHI2), flavanone 3-hydroxylase (CaF3H) and flavonoid 3'-hydroxylase $(\mathrm{CaF3} \mathrm{H})$ and $(\mathrm{C})$ anthocyanin late biosynthetic genes flavonoid 3', 5'-hydroxylase (CaF3'5'H), dihydroflavonol 4-reductase $(\mathrm{CaDFR})$, anthocyanin synthase (CaANS) and anthocyanidin 3-O-glucosyltransferase (CaUFGT). GUS-GO, MYB-GO and MYB-PO represent the pTRV2::GUS ovaries, purple spots of pTRV2::CaMYB101 ovaries and green parts of pTRV2::CaMYB101 ovaries, separately. 